\title{
In situ X-ray absorption spectroscopy as a unique tool for obtaining information on hydrogen binding sites and electronic structure of supported Pt catalysts: towards an understanding of the compensation relation in alkane hydrogenolysis
}

\author{
D.C. Koningsberger, ${ }^{\mathrm{a}, *}$ M.K. Oudenhuijzen, ${ }^{\mathrm{a}}$ J. de Graaf, ${ }^{\mathrm{a}, 1}$ J.A. van Bokhoven, ${ }^{\mathrm{a}, 2}$ \\ and D.E. Ramaker ${ }^{b}$ \\ a Department of Inorganic Chemistry and Catalysis, Debye Institute, Utrecht University, PO Box 80083, 3508 TB Utrecht, The Netherlands \\ ${ }^{\mathrm{b}}$ Chemistry Department, George Washington University, Washington, DC 20052, USA \\ Received 15 July 2002; revised 4 November 2002; accepted 20 November 2002
}

\begin{abstract}
$L_{2}$ and $L_{3}$ X-ray absorption near edge spectra (XANES) on supported Pt particles, with and without chemisorbed hydrogen, are shown to reflect the type of hydrogen-binding site on the Pt surface. FEFF8 ab initio multiple scattering calculations are used to determine XANES spectral fingerprints for the atop vs threefold $\mathrm{H}$ binding sites on Pt. Comparison of the experimental XANES data with the theoretical fingerprints, and further theoretical results, show that the acid/base properties of the support have a profound influence on the hydrogen coverage, and therefore on the mode of hydrogen adsorption on the Pt surface. As the electron richness of the support oxygen atoms increases (i.e., with increasing alkalinity of the support), the $\mathrm{H}$ coverage increases and the hydrogen-binding site of the strongly adsorbed hydrogen changes from atop to threefold. This site change is primarily responsible for the observed changes in previously reported kinetic data, which show an increase in negative order (roughly from -1.5 to -2.5 ) in hydrogen partial pressure for neopentane hydrogenolysis with increasing support alkalinity. This change in negative order directly reflects the greater number of vacant Pt sites that must be available to allow adsorption of the neopentane. A compensation relation is found in the kinetic data of Pt on different supports resulting directly from this change in hydrogen coverage. This implies that the experimentally determined kinetic parameters are apparent values. These apparent values are correlated to the intrinsic kinetic parameters via the thermodynamic properties of the sorption of the reactants, described by the Temkin equation. The TOF of neopentane hydrogenolysis over several catalysts, measured in previous work, decreases with the increasing alkalinity of the support. This can now be directly explained as the result of the change in hydrogen coverage using a Frumkin isotherm, implying that the neopentane adsorption becomes weaker with increased hydrogen coverage. These conclusions, that hydrogen drives the catalysis, are further supported by density functional calculations on small $\mathrm{Pt}_{4}$ clusters, which show that the acid/base properties of the support have a much larger direct influence on $\mathrm{Pt}-\mathrm{H}$ bonding than on $\mathrm{Pt}-\mathrm{CH}_{n}$ bonding.

(c) 2003 Elsevier Science (USA). All rights reserved.
\end{abstract}

Keywords: Pt $L_{2}$ and $L_{3}$ near edge spectra; Metal-support interaction; Hydrogen adsorption on Pt; Neo-pentane hydrogenolysis; Reaction order in hydrogen partial pressure; Compensation relation; Pt/LTL; Pt/NaY; Pt/H-USY

\footnotetext{
* Corresponding author.

E-mail address: d.c.koningsberger@chem.uu.nl (D.C. Koningsberger).

${ }^{1}$ Present address: Philips Research Laboratories Eindhoven, Prof. Holstlaan 4, 5656 AA Eindhoven, The Netherlands.

2 Present address: Laboratory for Technical Chemistry, ETH Hönggerberg, HCI E115, CH-8093, Zürich, Switzerland.
}

\section{Introduction}

Supported noble metal catalysts are used in a large number of commercially important applications, including hydrogenation, dehydrogenation, naphtha reforming, isomerization, hydrocracking, oxidation, automotive exhaust catalysts, and fuel cells [1]. Numerous studies have reported enhancements in the specific reaction rates of metal particles for benzene hydrogenation [2,3], propane hydrogenolysis [4], and neopentane hydrogenolysis and isomeriza- 
tion [5-7] on acidic supports compared to neutral supports. These differences are believed to be due to interaction between the metal particles and the support.

Several explanations for the metal-support interaction have been proposed in the literature: (i) formation of a metal-proton adduct [5,8], (ii) charge transfer between the metal atoms and the nearest neighbor zeolite oxygen atoms [9-12], and (iii) polarization of the metal particles by nearby cations of the support $[13,14]$. These explanations contains deficiencies: (i) proton adducts cannot account for an increase in electron density on the metal clusters in alkaline zeolites, (ii) significant direct transfer of electrons is very unlikely, as argued by Ponec et al. [15], and (iii) experiments underlying the theoretical calculations suggesting polarization by cations are lacking. Moreover, the explanations of the metal-support interaction mentioned above are superseded by more recent experimental and theoretical data as discussed below.

Systematic catalytic studies by our group, as summarized on the left side of Fig. 1, have shown that the turnover frequency (TOF) for neopentane conversion using supported noble metal particles (Pt, Pd) are greatly influenced by the properties of the support. The TOF of Pt increases with increasing acidity of mesoporous flat supports ( $\mathrm{MgO}-$ $\mathrm{Al}_{2} \mathrm{O}_{3}, \mathrm{SiO}_{2}, \mathrm{SiO}_{2}-\mathrm{Al}_{2} \mathrm{O}_{3}$ ) [16,17]. The TOF also increases for zeolite supports with (i) increasing number of protons $(\mathrm{Pt} / \mathrm{LTL}$ and $\mathrm{Pt} / \mathrm{Y})[17,18]$, (ii) increasing charge compensating cations $\left(\mathrm{Na}^{+} / \mathrm{K}^{+}\right.$in Pt/LTL [17]; $\mathrm{La}^{3+}$ in Pt/Y [18]), and (iii) increasing number of extra-framework $\mathrm{Al}$ in $\mathrm{Pt} / \mathrm{H}-$ USY [18]. The activity of Pt/NaY, Pt/NaLaY, Pt/NaH-USY, and $\mathrm{Pt} / \mathrm{H}-\mathrm{USY}$ for the hydrogenation of tetralin at $350^{\circ} \mathrm{C}$, in 60-bar hydrogen with 165 parts per million weight (ppmw) dibenzothiofene added to the feed, also depends on the composition of the zeolite support [19]. These process conditions

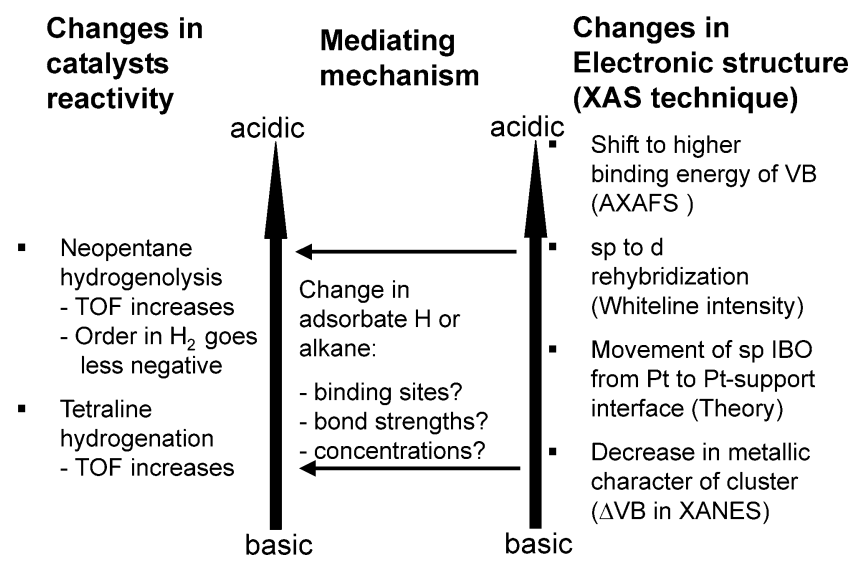

Fig. 1. (Right) Summary of electronic structure changes evident in a supported Pt particle (with the method of observation indicated in parenthesis) as a result of increasing acidity of the support. (Left) Summary of changes observed in the kinetics of two very different reactions involving adsorbed H. (Center) Possible changes in adsorbate structure and/or change in intrinsic or apparent kinetics, which might mediate the relationship between changes in the electronic structure of the metal particle and catalytic reactivity. are comparable to industrial conditions for deep hydrotreatment of diesel.

Recent work by our group $([19,20]$ and submitted articles) has also revealed that the nature of the metal-support interaction involves a change in the electronic properties of the metal cluster, induced by and correlated to the electron richness of the support oxygen atoms as summarized on the right side of Fig. 1. X-ray absorption fine structure data (XANES, Atomic XAFS) and density functional theory (DFT) calculations on supported Pt clusters reveal that the support influences the electronic properties of a metal particle in four separate ways:

(i) The complete Pt density of states (DOS) shifts to higher energy (lower binding energy) on basic supports and to lower energy on acidic supports, an effect directly reflected by the intensity of the experimental atomic XAFS (AXAFS) $[19,20]$ and by shifts in the XPS binding energies [20].

(ii) The Madelung potential of a basic support draws some $6 s$ and $6 p$ valence states below the Fermi level, where they consequently become filled at the expense of $5 d$ states. Effectively, upon going from an acidic to a basic support, rehybridization from, e.g., $5 d^{9} 6 s^{1}$ to $5 d^{8.5} 6 s^{1.5}$ occurs. This change is directly reflected in the intensity of the Pt $L_{3}$ whiteline and indicated by theoretical calculations ([21]; Oudenhuijzen, van Bokhoven, Ramaker, and Koningsberger, submitted).

(iii) The location of the $6 s, p$ interstitial bonding orbitals (IBO) moves from the surface (basic support) to the Pt-support interface (acidic), as reflected in density functional theory and molecular orbitals calculations ([21]; Oudenhuijzen, van Bokhoven, Ramaker, and Koningsberger, submitted).

(iv) The location of the insulator-to-metal transition with increasing cluster size is highly dependent on the acidity of the support. This metallic character of the particle is directly reflected in the spectral shape of the whiteline in the XANES data ([21]; Oudenhuijzen, van Bokhoven, Ramaker, and Koningsberger, submitted).

It seems obvious that these changes in the electronic structure within a supported $\mathrm{Pt}$ particle will affect the chemisorption of adsorbates such as $\mathrm{CH}_{x}$ and $\mathrm{H}_{2}$ on the surface. Consequently, the catalytic behavior of the $\mathrm{Pt}$ particles will be influenced by the alterations in the electronic structure induced by changes in the acid/base properties of the support.

In the literature it is generally observed that the reaction rate for alkane hydrogenolysis is first order in the alkane partial pressure, whereas the order in the hydrogen partial pressure is a strong function of both the type of catalyst and the process conditions and may be very negative [22]. In addition, it is observed that the apparent activation energy $E_{\text {app }}$ is correlated with the order in $P_{\mathrm{H}_{2}}$. For example, in ethane hydrogenolysis, a very negative order of -2.5 in $P_{\mathrm{H}_{2}}$ correlates with a high $E_{\text {app }}(225 \mathrm{~kJ} / \mathrm{mol})$, and a 
moderately negative order of -1.5 leads to a lower $E_{\text {app }}$ $(175 \mathrm{~kJ} / \mathrm{mol})$ [23]. The same results are found for the conversion of neopentane (2,2-dimethylbutane) to isopentane (isomerization) or isobutane and methane (hydrogenolysis) [24-27]. In addition to the correlation between the order in $P_{\mathrm{H}_{2}}$ and $E_{\text {app }}$, the compensation relation is regularly observed for hydrogenolysis reactions [28-30]. The compensation relation denotes a linear relationship between the apparent activation energy and the preexponential factor. This relationship is also called the Constable-Cremer relation [31]:

$\ln A_{\text {app }}=m E_{\text {app }}+c$.

One mechanism that can account for the compensation relation involves changes in the surface coverage or binding energies of the reactants as extensively discussed by Bond et al. [32]. These changes can alter the kinetic parameters, even if the true activation energy remains constant. The influence of the adsorption of the reactants on the observed activation energy $E_{\text {app }}$ is expressed by the Temkin equation [33],

$E_{\text {app }}=E_{\text {true }}+\sum n \Delta H$,

with $E_{\text {true }}$ the true, intrinsic activation energy and $\sum n \Delta H$ the sum of all the relevant adsorption enthalpies multiplied by the order $n$ of that reactant. Although the occurrence of a compensation relation is a widely accepted phenomenon in the catalytic literature, the reasons for this compensation relation are not understood and are still under debate.

This paper presents new experimental and theoretical results which, when combined with catalytic data presented in the literature, provide an increased understanding of the compensation relation. This paper will focus on the causal relationship between the changes in the electronic structure (itemized on the right) and the changes in the catalytic reactivity (itemized on the left side of Fig. 1). The changes in the electronic structure can alter (i) the chemisorption bond strength, (ii) the adsorption site, and/or (iii) the concentrations of adsorbates on the Pt surface. The changes in the electronic structure can lead to changes in the intrinsic and apparent kinetics. Analysis of Pt $L_{3}$ XANES data along with FEFF8 ab initio multiple scattering calculations will provide a signature of the $\mathrm{Pt}-\mathrm{H}$ binding sites. The XANES results show that the hydrogen adsorption site changes and ADF calculations indicate that also the $\mathrm{Pt}-\mathrm{H}$ bond strength changes, with the acid/base properties of the support. This implies that the concentration of adsorbate intermediates on the Pt surface depends on the acid/base properties of the support. The compensation relation and the change in the negative order in hydrogen as observed for alkane hydrogenolysis are induced by these changes.

\section{Methods}

\subsection{Experimental}

\subsubsection{Preparation and characterization of the supported Pt catalyst}

The $\mathrm{Pt} / \mathrm{Y}, \mathrm{Pt} / \mathrm{SiO}_{2}$, and $\mathrm{Pt} / \mathrm{ASA}$ catalysts were prepared by ion exchange or impregnation of supports with an aqueous solution of $\mathrm{Pt}\left(\mathrm{NH}_{3}\right)_{4}\left(\mathrm{NO}_{3}\right)_{2}$ (Aldrich 27,872-6 p.a.). Commercial $\mathrm{NaY}$ (LZY 54) and $\mathrm{NH}_{4}$-USY (LZY 84) zeolite powders without binder, obtained from UOP, and Silica (Aerosil 300) obtained from Degussa were used. $\mathrm{Pt}$ was applied via ion-exchange on these supports. Silica alumina (HA 100 5P) from Ketjen was impregnated with the precursor solution. After application of the Pt precursor, the samples were dried at $150^{\circ} \mathrm{C}$, calcined to $300^{\circ} \mathrm{C}$ ( $\mathrm{Pt} / \mathrm{NaY}, \mathrm{Pt} / \mathrm{SiO}_{2}$, and $\mathrm{Pt} / \mathrm{ASA}$ catalysts $)$, or $350^{\circ} \mathrm{C}(\mathrm{Pt} / \mathrm{H}-$ USY catalyst), and subsequently reduced in hydrogen at $400^{\circ} \mathrm{C}$. The $\mathrm{Pt} / \mathrm{Y}$ samples used for XAFS spectroscopy were calcined using a very low heating rate of $0.2^{\circ} \mathrm{C} / \mathrm{min}$. This was necessary to obtain highly dispersed $\mathrm{Pt}$ particles with a narrow particle size distribution [34].

The Pt/LTL catalysts were prepared by varying the acidity/alkalinity of the LTL zeolite supports, either impregnating a commercial K-LTL zeolite with $\mathrm{KNO}_{3}$ or exchanging with $\mathrm{NH}_{4} \mathrm{NO}_{3}$ to give $\mathrm{K} / \mathrm{Al}$ ratios ranging from 0.63 to 1.25 for Pt/LTL. Each LTL zeolite was calcined at $225^{\circ} \mathrm{C}$. Platinum was added by incipient wetness impregnation using an aqueous solution of $\left(\mathrm{Pt}\left(\mathrm{NH}_{3}\right)_{4}\right)\left(\mathrm{NO}_{3}\right)_{2}$, followed by drying at $125^{\circ} \mathrm{C}$. The catalysts are designated $\operatorname{Pt} / \operatorname{LTL}(x)$, with $x$ representing the $\mathrm{K} / \mathrm{Al}$ molar ratio.

The Pt/Y samples were further characterized by XRD, hydrogen chemisorption, TEM, EXAFS, and Pt particle modeling to determine the Pt dispersion, (average) Pt particle size, and size distribution, as described in detail elsewhere [34]. The Pt/LTL samples were investigated in detail by hydrogen chemisorption, EXAFS, FTIR of chemisorbed $\mathrm{CO}$, and XPS [20].

\subsubsection{Conversion of neopentane}

The conversion of neopentane was measured in a fixed bed reactor at $250^{\circ} \mathrm{C}, 1$ bar total pressure with 1 vol\% neopentane in hydrogen. In order to account for deactivation on Pt/H-USY, the activity and selectivity were determined by extrapolating conversion and selectivity to time zero. The activity (mole $/ \mathrm{s} * \mathrm{~g}_{\text {catalyst }}$ ) was calculated from the conversion of neopentane $(<10 \%)$ and the used space velocity ( $\mathrm{ml}$ feed $\left./ \mathrm{s} * \mathrm{~g}_{\text {catalyst }}\right)$.

The (apparent) activation energies and preexponential factors $\left(E_{\text {app }}\right.$ and $A_{\text {app }}$ ) of $\mathrm{Pt} / \mathrm{NaY}, \mathrm{Pt} / \mathrm{SiO}_{2}$, and $\mathrm{Pt} / \mathrm{ASA}$ were determined by measuring the conversions (values up to $15 \%$ were used) as a function of temperature in the range $250-300^{\circ} \mathrm{C}$. Since the $\mathrm{Pt} / \mathrm{H}-\mathrm{USY}$ catalyst deactivates with time on stream, the conversion values as a function of temperature for this catalyst were obtained from isothermic experiments by extrapolating the conversion to zero time. 
The Arrhenius constants were calculated using the TOF calculated from the activity (mole reactant/mole $\mathrm{P} t * \mathrm{~s}$ ) and $\mathrm{H} / \mathrm{Pt}_{\text {strong. }}$.

\subsubsection{XAFS spectroscopy}

The X-ray absorption spectra at the $\mathrm{Pt} L_{3}$ and $L_{2}$ edges were collected at the Wiggler Station 9.2 of the SRS (Daresbury, UK), using a $\mathrm{Si}(220)$ double crystal monochromator. Experiments were also performed at the ESRF (Grenoble, France) at BM29, using a $\mathrm{Si}(311)$ crystal. The monochromator was detuned to $70 \%$ of maximum intensity. All measurements were performed in transmission mode using ion chambers filled with Ar to have an X-ray absorbance of $20 \%$ in the first and of $80 \%$ in the second ion chamber. The samples were pressed into self-supporting wafers (calculated to have an absorbency of 2.5) and placed in a controlled atmosphere cell operated at $1 \mathrm{~atm}$ [35]. The $\mathrm{Pt} / \mathrm{Y}$ samples were reduced in flowing hydrogen at $400{ }^{\circ} \mathrm{C}$ (heating rate $5^{\circ} \mathrm{C} / \mathrm{min}$ ) for $1 \mathrm{~h}$ and cooled to liquid nitrogen temperature in hydrogen, when spectra were taken. The samples were subsequently evacuated at $200^{\circ} \mathrm{C}$ for $1 \mathrm{~h}$ and XAFS spectra were recorded at liquid nitrogen temperature, maintaining a vacuum of better than $2 \times 10^{-5} \mathrm{~Pa}$. The Pt/LTL catalysts were reduced in $\mathrm{H}_{2}$ at $300^{\circ} \mathrm{C}$ and XAFS spectra were recorded in $\mathrm{H}_{2}$ at liquid nitrogen temperature. A subsequent treatment in flowing $\mathrm{He}$ for $1 \mathrm{~h}$ at $300{ }^{\circ} \mathrm{C}$ was used to remove chemisorbed hydrogen, followed by XAFS experiments in $\mathrm{He}$ at liquid nitrogen temperatures.

\subsection{Theory and $\mathrm{Pt}_{4}$ model cluster}

Two quite different, but complementary, theoretical calculations are performed on model clusters to interpret the XANES data and understand the results. Density functional calculations (DFT) are utilized to calculate adsorbate-Pt bond energies and optimal adsorbate binding sites. Slater type orbitals are used to represent the atomic orbitals, with basis sets consisting of triple- $\zeta$ quality, extended with two polarization functions. As such these calculations represent the bonding orbitals well, and give good estimates of the bond energies and optimal binding sites on Pt as shown elsewhere ([21]; Oudenhuijzen, van Bokhoven, Ramaker, and Koningsberger, submitted). However, these calculations do not adequately approximate the antibonding and continuum orbitals 10-50 above the Fermi level, necessary to interpret the XANES data. Therefore, real-space full multiple scattering calculations utilizing a muffin-tin potential are also performed. These calculations effectively approximate the continuum orbitals, and because of the full multiple scattering, also reasonably approximate the strong antibonding resonances present in this energy region. However, the latter calculations do not allow accurate estimates of the bond energies or binding sites.

The Amsterdam Density Functional Package (ADF) [36] was used to perform the DFT calculations. Relativistic effects were accounted for, with details of the calculations reported elsewhere ([21]; Oudenhuijzen, van Bokhoven, Ramaker, and Koningsberger, submitted). To enhance computational efficiency, several atomic core shells of the Pt atoms were frozen, up to and including the Pt $4 d$ level. The geometry optimizations that were performed were carried out in the spin-restricted mode including scalar relativistic effects, thereby excluding spin-orbit effects. The numerical integration precision applied was set to 5.5 significant digits. The applied criteria for the geometry optimization were $1 \times 10^{-3}$ hartree for the changes in energy, $1 \times 10^{-4}$ hartree $/ \AA$ for changes in the energy gradients, and $1 \times 10^{-2} \AA$ for changes in the Cartesian coordinates.

The FEFF8 code [37] was used to perform the ab initio self-consistent field, real-space, full multiple scattering calculations. FEFF8 implements self-consistent field potentials for the determination of the Fermi level and the charge transfer. The calculations were performed using the HedinLundquist exchange correlation potential. A core-hole is included on the absorber atom in order to mimic the final state of the photon absorption process.

The theoretical calculations were performed on a tetragonal $\mathrm{Pt}_{4}$ cluster. To mimic the support, three $\mathrm{X}_{2} \mathrm{O}$ molecules were placed underneath the $\mathrm{Pt}_{4}$ cluster in a triangular arrangement, as shown in Fig. 2. Here $\mathrm{X}=\mathrm{F}, \mathrm{H}$, and $\mathrm{Na}$ to mimic acidic, neutral, and basic supports, respectively (i.e., in these calculations the $\mathrm{Al}$ and $\mathrm{Si}$ atoms, along with the counterions of the support, having different acidities, were mimicked by $\mathrm{F}, \mathrm{H}$, and $\mathrm{Na}$ atoms). The geometries of these clusters were fully optimized in the ADF calculations to obtain reasonable estimates of the $\mathrm{Pt}$-adsorbate bond energies. The optimized geometries are reported elsewhere, with the results reflecting $\mathrm{Pt}-\mathrm{H}$ and $\mathrm{Pt}-\mathrm{O}$ bond lengths typical of that found from the EXAFS results and other reported theoretical results. In contrast the FEFF8 calculations used to calculate

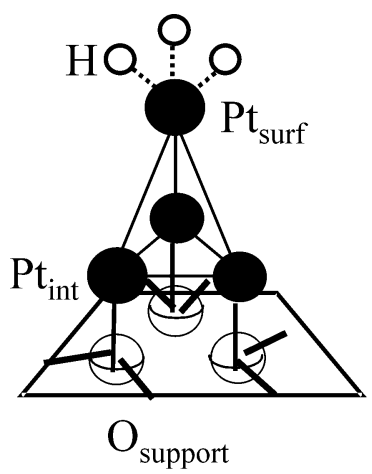

Atop

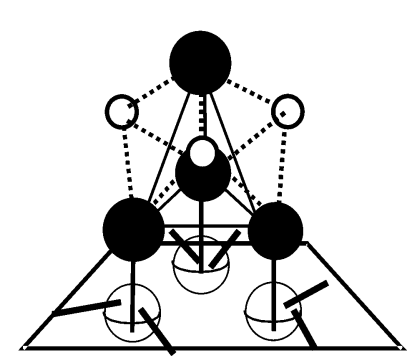

3-fold
Fig. 2. Structure of tetrahedral $\mathrm{Pt}_{4}$ clusters utilized in the FEFF8 and $\mathrm{ADF}$ calculations with the three $\mathrm{H}$ atoms adsorbed in either the atop or threefold sites ( $3 \mathrm{H}$ atoms only in FEFF8 calculations) and the three $\mathrm{X}_{2} \mathrm{O}$ molecules mimicking the support oxygen atoms and backbonds to the $\mathrm{Si}$ or $\mathrm{Al}$ in the support (the latter here mimicked by $\mathrm{X}=\mathrm{F}, \mathrm{H}$, or $\mathrm{Na}$ atoms for acidic to basic supports, respectively, in ADF, with $\mathrm{X}=\mathrm{H}$ in the FEFF8 calculations). The geometries were optimized in the ADF calculations, but not in the FEFF8. 
XANES were performed with the $\mathrm{X}_{2} \mathrm{O}$ molecules all water molecules (i.e., $X=H$ ), because the SCF procedure utilized in FEFF8 does not give reasonable charge transfers with the $\mathrm{Na}$ and $\mathrm{F}$ atoms. Further, calculations with $\mathrm{X}=\mathrm{Na}$ and $\mathrm{F}$ are not necessary since the acidity of the support in these XANES calculations does not significantly alter the calculated DOS with fixed $\mathrm{H}$ binding site (atop or threefold). The ADF calculations (Oudenhuijzen, van Bokhoven, Ramaker, and Koningsberger, submitted) show that the water molecules in the latter FEFF8 calculation are not necessarily in an optimal arrangement, but they do reasonably mimic the support for these latter calculations.

The average Pt-Pt and Pt-O coordination numbers for these $\mathrm{Pt}_{4} / \mathrm{X}_{6} \mathrm{O}_{3}$ clusters are 3 and 0.75 , respectively. The $\mathrm{Pt}$ clusters in the LTL and Y supports are very small and have average Pt-Pt coordination numbers of around 4 to 6 . The $\mathrm{Pt}-\mathrm{O}$ coordination number here is somewhat bigger than that seen in the experimental data (typically $0.2-0.5$ ). To mimic the effects of adsorbed hydrogen, $1-3 \mathrm{H}$ atoms were placed on the cluster. In the FEFF8 calculations (no geometry optimization), the atop site hydrogen adsorption was mimicked by placing all three hydrogens on the surface Pt atom as pictured in Fig. 2, giving an average Pt-H coordination number of 0.75 . Threefold site hydrogen adsorption was realized by placing a hydrogen in each of the threefold sites (see Fig. 2), leading to an average $\mathrm{Pt}-\mathrm{H}$ coordination number of 2.25 . In both cases the $\mathrm{Pt}-\mathrm{H}$ distance was fixed at $1.9 \AA$. The oxygen atoms are placed $2.2 \AA$ from the Pt atoms in the $\mathrm{Pt}_{4}$ cluster, distances typically found in the EXAFS data. Of course in the geometry optimized ADF calculations, these geometries were significantly altered, but the $\mathrm{Pt}-\mathrm{H}$ bond length, critical for the XANES calculations, stays nearly the same.

Two different types of $\mathrm{Pt}$ atoms can be distinguished in the supported $\mathrm{Pt}_{4}$ cluster: $\mathrm{Pt}_{\text {surf }}$ and $\mathrm{Pt}_{\text {int }}$. The theoretical $\mathrm{X}$-ray spectrum of the supported cluster $(\mu)$ was obtained by calculating $\mu\left(\mathrm{Pt}_{\text {surf }}\right)$ and $\mu\left(\mathrm{Pt}_{\mathrm{int}}\right)$ followed by averaging; $\mu=\frac{1}{4} \mu\left(\mathrm{Pt}_{\text {surf }}\right)+\frac{3}{4} \mu\left(\mathrm{Pt}_{\text {int }}\right)$, as would be reflected in an experimental spectrum.

\subsection{Pt $L_{3}$ edge analysis procedures and binding site fingerprints}

It is well known that the Pt $L_{3}$ XANES is sensitive to the adsorption of $\mathrm{H}$ [38-41]. To isolate and identify these rather small changes, difference spectra $\Delta \mu$ are obtained by taking the difference between the $L_{3}$ spectra with and without $\mathrm{H}$, $\Delta \mu=\mu(\mathrm{H} / \mathrm{Pt})-\mu(\mathrm{Pt})$, with $\mu(\mathrm{H} / \mathrm{Pt})$ the $L_{3}$ edge spectrum in the presence of $\mathrm{H}_{2}$ and $\mu(\mathrm{Pt})$ the $L_{3}$ edge spectrum in vacuum. Since the absorption $\mu$ equals $\mu_{0}(1+\chi)$, the total change can be expressed as

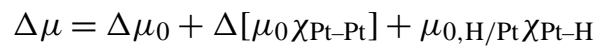

with $\Delta \mu$ : the difference $L_{3}$ spectrum, $\Delta \mu_{0}$ : changes in the atomic $L_{3}$ XAFS, $\Delta\left(\mu_{0} \chi_{\mathrm{Pt}-\mathrm{Pt}}\right)$ : changes in the Pt-Pt total scattering induced by $\mathrm{H}_{2}$ chemisorption, i.e., $\left(\mu_{0} \chi_{\mathrm{Pt}-\mathrm{Pt}}\right)$ in the presence of $\mathrm{H}$ minus that in the absence of $\mathrm{H}$,

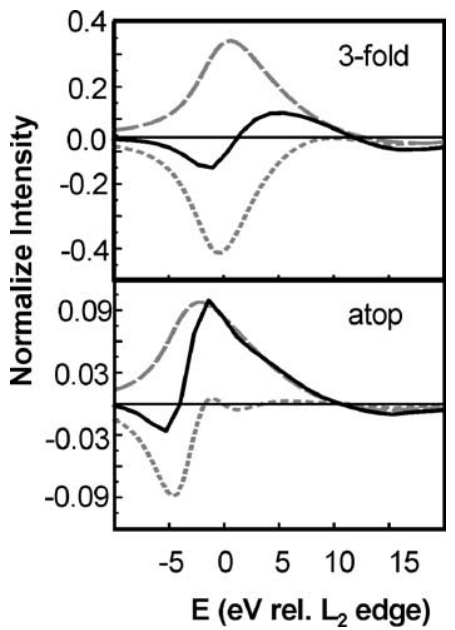

Fig. 3. The calculated $\Delta \mu_{L_{3}}=\mu(\mathrm{H} / \mathrm{Pt})-\mu(\mathrm{Pt})$ signature (black solid line), as defined in Eq. (3) and obtained from FEFF8 results on the clusters shown in Fig. 2. The $\mathrm{Pt}-\mathrm{H}$ scattering contribution $\left(\mu_{0, \mathrm{H} / \mathrm{Pt}} \chi_{\mathrm{Pt}-\mathrm{H}}\right)$ (gray dashed light) and change in Pt-Pt contribution $\left(\Delta\left[\mu_{0} \chi_{\mathrm{Pt}}-\mathrm{Pt}\right]\right)$ (gray dotted lines) are also indicated. These theoretical results have been shifted by -1 (basic) and $-4 \mathrm{eV}$ (acidic) for better alignment with experimental data in Fig. 6.

$\mu_{0, \mathrm{H} / \mathrm{Pt}}$ : the free atom $L_{3}$ absorption (including atomic XAFS) in the presence of $\mathrm{H}_{2}$, and $\chi_{\mathrm{Pt}-\mathrm{H}}$ : the additional $\mathrm{Pt}-\mathrm{H}$ scattering. Both $\chi_{\mathrm{Pt}-\mathrm{Pt}}$ (with and without chemisorbed hydrogen) and $\chi_{\mathrm{Pt}-\mathrm{H}}$ include the full scattering, i.e., the single and the multiple scattering. The XANES is dominated by the multiple scattering contributions.

Fig. 3 shows the large negative $\Delta\left(\mu_{0} \chi_{\mathrm{Pt}-\mathrm{Pt}}\right)$ contribution (dotted line) obtained by FEFF8 calculations on our $\mathrm{Pt}_{4} / 3 \mathrm{H}_{2} \mathrm{O}$ cluster with a hydrogen atom placed in each of the threefold sites (see Fig. 2) using a basic support oxygen. The dashed line represents the $\mu_{0, \mathrm{H} / \mathrm{Pt}} \chi_{\mathrm{Pt}-\mathrm{H}}$ contribution. Since the $\Delta\left(\mu_{0} \chi_{\mathrm{Pt}-\mathrm{Pt}}\right)$ contribution dominates over the $\Delta \mu_{0}$ (not shown here), and the $\Delta \mu_{0}$ contribution is the least well predicted by the FEFF8 code because of the muffin-tin approximation made in that code, we ignore that contribution here. Therefore in this work, we include only the last two terms of Eq. (3). The solid line mimics the difference $L_{3}$ spectrum $(\Delta \mu)$. The large negative contribution of $\Delta\left(\mu_{0} \chi_{\mathrm{Pt}-\mathrm{Pt}}\right)$ makes $\Delta \mu$ negative at the low energy side of the difference spectrum. Placing the hydrogen atoms in the atop position (see Fig. 2) gives a significant change in the difference spectrum (see Fig. 3). Not only are the two dominant contributions much smaller, but the $\Delta\left(\mu_{0} \chi_{\mathrm{Pt}-\mathrm{Pt}}\right)$ term is less broadened, with a negative maximum at lower energy. The resulting difference spectrum has a strong positive signature at the high-energy side of the spectrum.

These results show the importance of changes in the $\mathrm{Pt} L_{3}$ XANES region due to the influence of chemisorbed $\mathrm{H}$ on the $\mathrm{Pt}-\mathrm{Pt}$ multiple scattering paths. When $\mathrm{H}$ atoms are adsorbed on the threefold hollow sites, hydrogen weakens the Pt-Pt bonding for $\mathrm{Pt}$ atoms beneath the $\mathrm{H}$ adsorption site. This bond weakening has been called $d$-electron frustration by Feibelman et al. [42], and Pt-Pt destabilization by Papoian 
et al. [43]. Fig. 3 shows that the $\Delta\left(\mu_{0} \chi_{\mathrm{Pt}-\mathrm{Pt}}\right)$ contribution is very much smaller when the $\mathrm{H}$ is bonded in the atop position, allowing the $\mathrm{Pt}-\mathrm{H}$ contribution to dominate. This is further confirmed by Papoian et al. [43] who find that $\mathrm{H}$ in the atop position does not induce the same $\mathrm{Pt}-\mathrm{Pt}$ destabilization as that found for the threefold $\mathrm{H}$. Notice that the spectral shape of the Pt-H scattering term is remarkably insensitive to the $\mathrm{H}$ binding site (its magnitude only changes because of the 2.25 average coordination for the threefold $\mathrm{H}$ vs 0.75 in the atop case).

The theoretically obtained fingerprints shown in Fig. 3 have been experimentally confirmed by Teliska et al. (submitted). In an electrochemical cell using a Pt electrode at very high and intermediate $\mathrm{H}$ coverage hydrogen is known to exist in atop and threefold sites, respectively. The experimental $\Delta \mu$ for these Pt electrodes showed the same change of the $\Delta \mu$ signature as was obtained from the FEFF8 calculations in Fig. 3. Many FEFF8 calculations on small $\mathrm{Pt}_{n}$ clusters (with $n=4-6$ ) with $\mathrm{H}$ adsorbed in the threefold [44, 45] and atop sites have been performed. All these calculations suggest that one of the critical factors that determine the relative size of the terms describing the variations in $\Delta \mu$ depends strongly on the $\mathrm{H}$ adsorption site. The other, less important factors influencing the overall $\Delta \mu$ include the cluster shape and size, the charge on the support atoms (e.g., alkalinity of the support), the $\mathrm{H}$ coverage, the $\mathrm{Pt}-\mathrm{H}$ bond distance, the placement of the Fermi level (i.e., whether the cluster is metallic or not), and the choice of potentials in FEFF8 (Hedin-Lundquist or Dirac-Hara). Nevertheless, the signature of $\Delta \mu$ appears to primarily reflect the adsorption site of $\mathrm{H}$ and other adsorbates.

In our earlier work $[18,20,41,46,47]$ reported prior to the availability of the FEFF8 code, we assumed that the

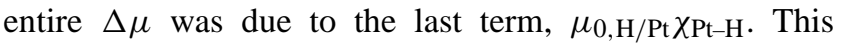
last term arises from the $\mathrm{Pt}-\mathrm{H}$ scattering, consisting of the single-scattering term, which dominates around $8 \mathrm{eV}$, and the multiple-scattering contribution, which is largest near the edge. We therefore attributed the large fluctuations in $\Delta \mu$ near the edge to changes in the $\mathrm{Pt}-\mathrm{H}$ multiple scattering, which we interpreted as arising from small changes in the $\mathrm{Pt}-\mathrm{H}$ anti-bonding state (AS) energy. This AS was assumed to cause a $\mathrm{Pt}-\mathrm{H}$ shape resonance arising from the interference between the resonantly and nonresonantly scattered photoelectron waves, which resulted in a Fanolike profile just above the edge. Furthermore, the changes in the AS energy were suggestive of the relative strength of the Pt-H bond. The FEFF8 calculations now show that the large fluctuations in spectral shape of $\Delta \mu$ arise instead from the interference between the $\mathrm{Pt}-\mathrm{H}$ and $\mathrm{Pt}-\mathrm{Pt}$ scattering, and thereby reflect hydrogen binding site information rather than $\mathrm{Pt}-\mathrm{H}$ bond strength. This implies that the new interpretation of $\Delta \mu$ leads to binding site information and can now more directly provide insight into catalytic reactions and kinetics than relative bond strengths.
Table 1

Neopentane conversion (250) and Arrhenius constants $\left(250-300^{\circ} \mathrm{C}\right)$

\begin{tabular}{lccccc}
\hline Catalyst & neo/s *Pt & $\begin{array}{c}\text { Hydrogenolysis } \\
\text { selectivity }\end{array}$ & $\begin{array}{c}\text { TOF } \\
\text { neo }\end{array}$ & $\begin{array}{c}E_{\text {app }} \\
\mathrm{kJ} / \mathrm{mole}\end{array}$ & $\ln A_{\text {app }}$ \\
\hline $\mathrm{Pt} / \mathrm{H}-\mathrm{USY}$ & $2.7 \times 10^{-3}$ & 0.44 & $8.8 \times 10^{-3}$ & 140 & 26.5 \\
$\mathrm{Pt} / \mathrm{NaY}$ & $1.3 \times 10^{-4}$ & 0.61 & $2.4 \times 10^{-4}$ & 182 & 32.9 \\
$\mathrm{Pt} / \mathrm{ASA}$ & $1.1 \times 10^{-3}$ & 0.76 & $2.4 \times 10^{-3}$ & 156 & 29.4 \\
$\mathrm{Pt} / \mathrm{SiO}_{2}$ & $4.0 \times 10^{-5}$ & 0.61 & $9.5 \times 10^{-5}$ & 194 & 34.7 \\
\hline
\end{tabular}

\section{Results}

\subsection{Kinetics}

The activities/mole (neopentane converted per second per $\mathrm{kg}$, per mole $\mathrm{Pt}$ ), hydrogenolysis selectivity, and TOF for the hydrogenolysis of neopentane are given in Table 1. The activities increase in the order $\mathrm{Pt} / \mathrm{SiO}_{2}<\mathrm{Pt} / \mathrm{NaY}<$ $\mathrm{Pt} / \mathrm{ASA}<\mathrm{Pt} / \mathrm{H}-\mathrm{USY}$. The TOFs for the hydrogenolysis of neopentane relative to $\mathrm{Pt} / \mathrm{SiO}_{2}$ are $\mathrm{Pt} / \mathrm{SiO}_{2}=1, \mathrm{Pt} / \mathrm{NaY}=$ 1.6, Pt/ASA $=19, \mathrm{Pt} / \mathrm{H}-\mathrm{USY}=41$. The Arrhenius plots of the TOFs of neopentane hydrogenolysis are shown elsewhere ([48]; de Graaf, van Bokhoven, and Koningsberger, in preparation). They show an isokinetic temperature. In Table 1 the apparent activation energies $\left(E_{\mathrm{app}}\right)$ and the natural logarithm of the preexponential factors $\left(\ln A_{\mathrm{app}}\right)$, calculated from these Arrhenius plots, are given. The error in $E_{\text {app }}$ and $\ln A_{\text {app }}$, as estimated from the accuracy of the determination of the conversion and temperature, is at a maximum $10 \%$ for both parameters. The $E_{\text {app }}$ for the total conversion of neopentane increases in the order Pt/H-USY < $\mathrm{Pt} / \mathrm{ASA}<\mathrm{Pt} / \mathrm{NaY}<\mathrm{Pt} / \mathrm{SiO}_{2}$. The difference between the highest and the lowest values for $E_{\text {app }}$ is $54 \mathrm{~kJ} / \mathrm{mole}$. The $\ln A_{\text {app }}$ increases in the same order, Pt/H-USY $<\mathrm{Pt} / \mathrm{ASA}<$ $\mathrm{Pt} / \mathrm{NaY}<\mathrm{Pt} / \mathrm{SiO}_{2}$. The change in $E_{\text {app }}$ and $\ln A_{\text {app }}$ is opposite the change in TOF for these catalysts. A higher TOF is paralleled with lower $E_{\text {app }}$ and $\ln A_{\text {app }}$.

In Fig. 4 the $\ln A_{\text {app }}$ is plotted as a function of $E_{\text {app }}$. It can be seen that the data points obey the ConstableCremer isokinetic relation as given in Eq. (1): an increase in $E_{\text {app }}$ is compensated for by an increase in $\ln A_{\text {app. The }}$ observation that all Arrhenius parameters for all catalysts obey the Constable-Cremer relation [31] indeed suggest that compensation behavior is present. According to the

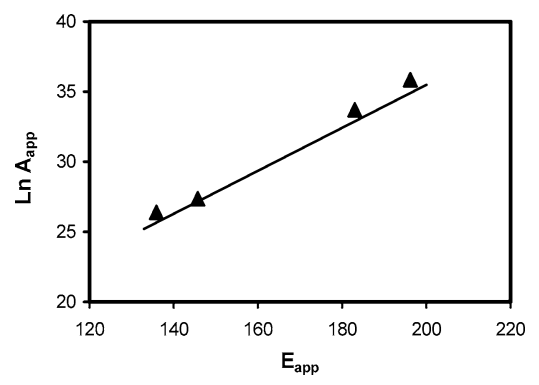

Fig. 4. Constable plot: $\ln A_{\text {app }}$ versus $E_{\text {app }}$ for hydrogenolysis of neopentane on the indicated catalysts. 

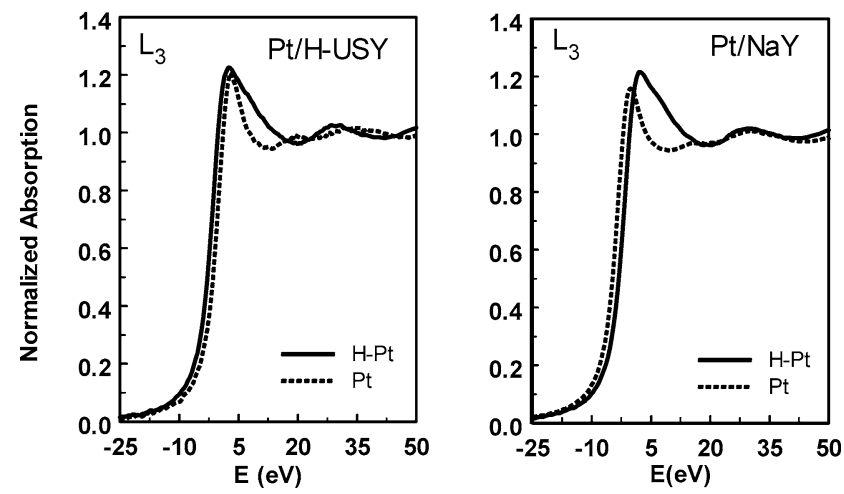

Fig. 5. Comparison of the $L_{3} \mathrm{X}$-ray absorption edges, $\mu$ (aligned as described elsewhere [44]), for $\mathrm{Pt} / \mathrm{NaY}$ and $\mathrm{Pt} / \mathrm{H}-\mathrm{USY}$ after reduction in flowing $\mathrm{H}_{2}$ at $400{ }^{\circ} \mathrm{C}(\mathrm{H} / \mathrm{Pt})$ and after evacuation at $200^{\circ} \mathrm{C}$ for $1 \mathrm{~h}(\mathrm{Pt})$.

standards set by Bond et al. [32], the range in $E_{\text {app }}$ should ideally be at least $50 \%$ of the smallest $E_{\text {app }}$ measured, which is close to the value of $40 \%$ for the results presented in this study.

\subsection{Analysis of Pt $L_{3}$ edges: signature of the hydrogen binding site}

The Pt $L_{3}$ X-ray absorption edges obtained on $\mathrm{Pt} / \mathrm{NaY}$ and Pt/H-USY are shown in Fig. 5. All spectra are aligned relative to the reference, the $L_{2}$ edge spectrum for "clean" Pt clusters, in order to account for initial and final state effects [41]. The $L_{2}(\mathrm{H} / \mathrm{Pt})$ and $L_{2}(\mathrm{Pt})$ edges were aligned at step height 0.6 , whereas both the $L_{3}(\mathrm{H} / \mathrm{Pt})$ (solid lines) and the $L_{3}(\mathrm{Pt})$ (dotted lines) edges were aligned with the help of the EXAFS oscillations relative to the $L_{2}$ edges. The edge position and the intensity of the Pt nearedge absorption are clearly influenced by chemisorbed hydrogen.

The signatures $\left(\Delta \mu_{L_{3}}\right)$ for the hydrogen adsorption site on the Pt/H-USY and Pt/NaY samples are given in Fig. 6 with dashed lines. The solid lines show the $\Delta \mu_{L_{3}}$ for

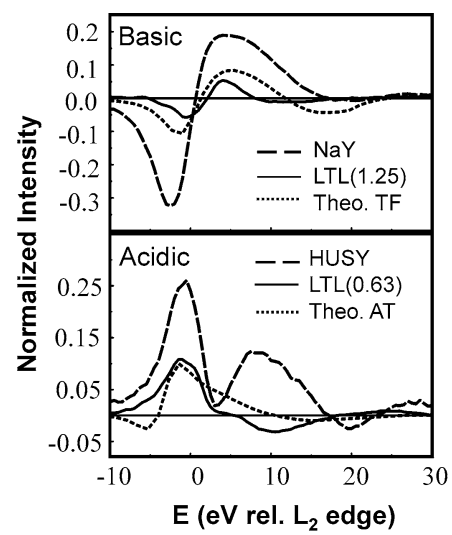

Fig. 6. Comparison of the experimental $\Delta \mu_{L_{3}}=\mu_{L_{3}}(\mathrm{H} / \mathrm{Pt})-\mu_{L_{3}}(\mathrm{Pt})$ signatures for $\mathrm{Pt} / \mathrm{NaY}$ and $\mathrm{Pt} / \mathrm{HUSY}$ (i.e., by subtracting the data in Fig. 5 for the NaY and HUSY supports) and for similar Pt/LTL(x.X) (x.X indicating $\mathrm{K} / \mathrm{Al}$ ratio data) with the theoretical FEFF8 fingerprints obtained from Fig. 3.
Pt/LTL(0.63) and Pt/LTL(1.25). The $\Delta \mu_{L_{3}}$ signatures for $\mathrm{Pt} / \mathrm{NaY}$ and Pt/LTL(1.25) are the same. Likewise, the lowenergy part of the signature for $\mathrm{Pt} / \mathrm{H}-\mathrm{USY}$ resembles the low-energy part of the $\Delta \mu_{L_{3}}$ obtained for Pt/LTL(0.63). It can clearly be seen that the signatures are strongly influenced by the acid/base properties of the support and by the coverage with $\mathrm{H}$ atoms. The $\mathrm{Pt} / \mathrm{L}$ data were reduced in $\mathrm{H}$ at $300^{\circ} \mathrm{C}$ and heated in $\mathrm{He}$ at $300^{\circ} \mathrm{C}$ to drive off a small part of the $\mathrm{H}$. This means that not nearly as much $\mathrm{H}$ was removed as for the vacuum treatment performed on the Y samples; hence the much smaller amplitude for $\Delta \mu$ in the LTL case, in spite of the smaller cluster sizes. The unscaled theoretical fingerprints for threefold and atop $\mathrm{H}$ from Fig. 3 are plotted in Fig. 6 with a dotted line. Generally good agreement is obtained considering the relative insensitivity of electron scattering to $\mathrm{H}$, and hence the small differences $(0.6$ to $3 \%)$ in the $\mathrm{H} / \mathrm{Pt}$ and $\mathrm{Pt}$ spectra. The comparison of the results obtained by the FEFF8 code with the experimental data indicates that the hydrogen binding site on basic supports is threefold and atop on acid supports.

Fig. 7 shows the experimental signature for the adsorption of hydrogen on $\mathrm{Pt}$ particles dispersed on the neutral LTL(0.96) support. It was possible to fit the experimentally obtained difference spectra with the experimentally obtained signatures for atop (Pt/LTL(0.63); acidic) and threefold (Pt/LTL(1.25); basic):

Exp. $=0.5 \mathrm{Pt} / \mathrm{LTL}(0.63)+0.7 \mathrm{Pt} / \operatorname{LTL}(1.25)$.

The fit results are given in the top part of Fig. 7 with a dotted line. By using the theoretically obtained signatures the following fit can be obtained:

Theor. $=0.2\left(\mathrm{H}_{\text {atop-acidic }}\right)+0.45\left(\mathrm{H}_{\text {threefold }}\right.$-basic $)$.

Again reasonable agreement is obtained, except for the differences around $10 \mathrm{eV}$. The reason for this difference between the fit and experiment in this region is not clear. However, the results strongly suggest that for $\mathrm{Pt}$ particles dispersed on neutral supports hydrogen adsorbs on both atop and threefold Pt sites. The relative coefficients obtained

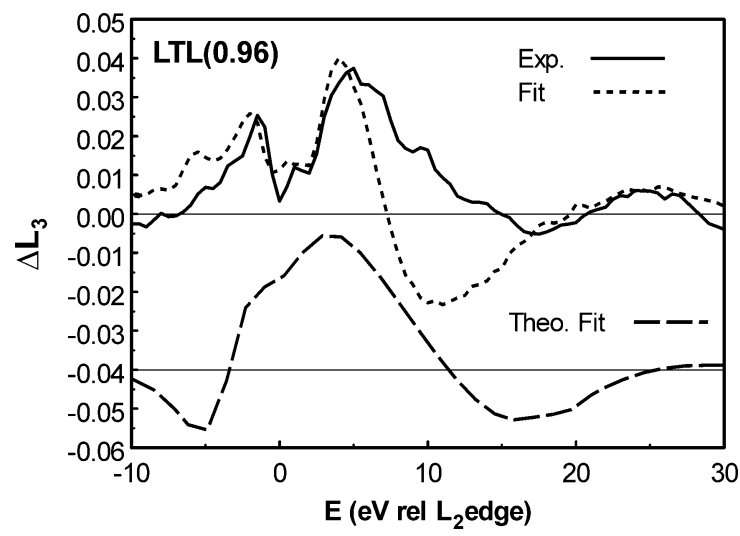

Fig. 7. Comparison of the $\Delta \mu_{L_{3}}$ data for Pt/LTL(0.96) with the optimal fits described by Eqs. (4) and (5). 


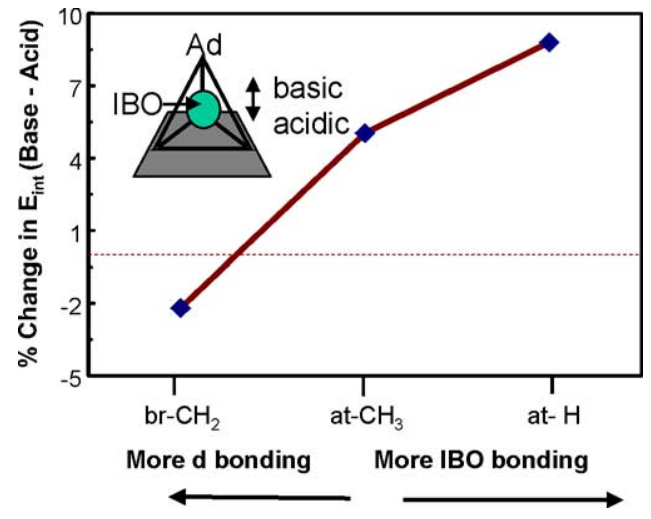

Fig. 8. Plot of the percent change in bond strength equal to $\left[E_{\text {int }}(\right.$ basic $)-E_{\text {int }}($ acidic $\left.)\right] /\left[E_{\text {int }}\right.$ (basic $)+E_{\text {int }}($ acid $\left.)\right] \times 200$, where the $E_{\text {int }}$, as defined by Eqs. (6) and (7), have been calculated by the ADF code as reported in [21]. Also illustrated are the $\mathrm{Pt}_{4}$ cluster and movement of the IBO with support acidity, which is primarily responsible for the decrease in $\mathrm{Pt}-\mathrm{H}$ bond strength with acidity (i.e., increase with alkalinity).

from the fit with the theoretical $\Delta \mu_{L_{3}}$ curves suggest that the strongly bonded $\mathrm{H}$ still on the surface under reaction conditions does not move to the atop sites near the cluster edges until the support becomes very acidic, since nearly $70 \%$ of the $\mathrm{H}$ is still in the threefold sites for neutral supports.

\subsection{Effect of support acid/base properties on Pt-C and $\mathrm{Pt}-\mathrm{H}$ bond strength and hydrogen coverage}

Density functional theory (DFT) results were obtained on supported $\mathrm{Pt}_{4} / \mathrm{X}_{2} \mathrm{O}$ clusters similar to those shown in Fig. 2, with the geometry of these clusters fully optimized in the ADF calculations. The "intrinsic bond energies" used to obtain the results in Fig. 8 reflect the energy required to remove a fragment adsorbed on the $\mathrm{Pt}_{4}$ cluster to the gas phase. It is given by

$$
\begin{aligned}
& E_{\text {int, } \mathrm{CH}_{n}=}=E_{\mathrm{Pt}_{4}-\mathrm{CH}_{n} / \mathrm{X}_{2} \mathrm{O}}-E_{\mathrm{CH}_{n}}-E_{\mathrm{Pt}_{4} / \mathrm{X}_{2} \mathrm{O}} \\
& \\
&\left(\mathrm{CH}_{n} \text { bonding }\right) \text { or } \\
& E_{\mathrm{int}, \mathrm{H}}= E_{\mathrm{Pt}_{4}-\mathrm{H} / \mathrm{X}_{2} \mathrm{O}}-E_{\mathrm{H}}-E_{\mathrm{Pt}_{4} / \mathrm{X}_{2} \mathrm{O}} \text { (H bonding). }
\end{aligned}
$$

The results in Fig. 8 show that the $\mathrm{H}$ bonding undergoes a greater percent weakening than the $\mathrm{C}$ bonding with increasing support acidity. This occurs because the $\mathrm{Pt}-\mathrm{H}$ bonding has a stronger Pt $s p$ component than the bonding with a $\mathrm{C}$ atom. In contrast, the bonding of $\mathrm{Pt}$ with various alkane radicals (i.e., alkanes with one $\mathrm{H}$ removed) appears to be generally determined by localized bonding between the carbons and the Pt $5 d$ orbitals. This is consistent with reported GVB-MO calculations [49], which also indicate that the $\mathrm{Pt}-\mathrm{H}$ bond has a strong overlap with $\mathrm{Pt} 6 s p$ orbitals. In the valence-bond picture, an interstitial bond orbital (IBO) exists in the interstitial region of a Pt tetrahedral, as illustrated in the insert of Fig. 8. Increased support acidity polarizes the Pt cluster with a resultant rearrangement of the IBO toward the support and reduces the overlap with

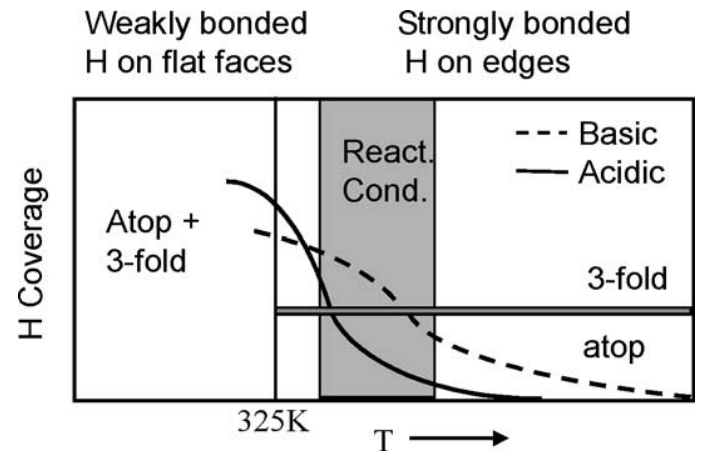

Fig. 9. Schematic of the $\mathrm{H}$ coverage as a function of temperature illustrating the increased coverage of $\mathrm{H}$ on basic supports compared with acidic, and the transition between weakly bonded $\mathrm{H}$ (that desorbing below $325 \mathrm{~K}$ ) and strongly bonded $\mathrm{H}$. The increased strongly bonded $\mathrm{H}$ coverage causes the $\mathrm{H}$ to prefer the threefold position where it does not have to share Pt edge sites with other H. Details of these calculations in (Oudenhuijzen, van Bokhoven, Ramaker, and Koningsberger, submitted).

the adsorbate. A shift to higher binding energy of the Pt $5 d$ orbitals also alters the strength of the $\mathrm{Pt}-\mathrm{C}$ bond; in fact, in the case of the bridge-bonded $\mathrm{CH}_{2}$ it strengthens the $\mathrm{Pt}-\mathrm{C}$ bond.

These results indicate that it is the $\mathrm{Pt}-\mathrm{H}$ bond that is most influenced by the acid/base properties of the support. It has important consequences for the hydrogen coverage under reaction conditions, as is schematically shown in Fig. 9. This figure is based upon further ADF calculations (Oudenhuijzen, van Bokhoven, Ramaker, and Koningsberger, submitted) with 1, 2, and 3 hydrogen atoms adsorbed on the $\mathrm{Pt}_{4} / \mathrm{X}_{2} \mathrm{O}$ cluster in the atop, bridged, and threefold sites, respectively. At low coverage $(1 \mathrm{H})$ the optimal site is atop, whereas with $3 \mathrm{H}$ the optimal site is threefold. This strongly suggests that the hydrogen binding site is dictated by the hydrogen coverage. Fig. 9 makes clear why under reaction conditions hydrogen binds in the atop site on acidic supports and in the threefold sites on basic supports. Although the Pt XANES data were not collected at reaction temperature they indicate the same trend. EXAFS results on the Pt/Y and Pt/LTL catalysts used in this study show very small Pt particle sizes (Pt-Pt coordination number 4-5.5) [18,20]. For large Pt particles (with more flat faces) the threefold to atop signature change occurs only above $373 \mathrm{~K}$ [20], after all weakly bonded hydrogen on the flat faces is removed. For the small Pt particles in Pt/Y and Pt/LTL, almost all hydrogen is adsorbed near edges and hence is strongly bonded. The signature change is due to the strongly bonded hydrogen and therefore the signature change occurs already at very low temperature.

\section{Discussion}

\subsection{Neopentane conversion}

Neopentane hydrogenolysis is a monofunctional probe reaction, only dependent on the catalytic activity of the 
metal [50,51], as is confirmed by the primary reaction products: methane, isobutane (hydrogenolysis), and isopentane (isomerization). Neopentane cannot undergo a bifunctional mechanism because the neopentane molecule cannot form an alkene intermediate. Moreover, neopentane does not undergo protolytic cracking at the temperatures used for the catalytic reaction $\left(250^{\circ} \mathrm{C}\right)$. Therefore, the changes in the TOF cannot be ascribed to a bifunctional mechanism. The results presented here and those shown previously by our group [16-19] show that the TOF of neopentane hydrogenolysis over supported Pt catalysts strongly depends on the acid/base properties and composition of the support. Detailed studies ([48]; de Graaf, van Bokhoven, and Koningsberger, in preparation) also show that the increase in TOF of both reactions cannot be related to a change in absorption directly onto the support or to diffusion limitations in the support. Further, the influence of Pt particle size is observable, but it is not the dominant effect. All these results strongly indicate that only Pt catalyzes the conversion of neopentane and that the acid/base properties and the composition of the support are the most important factors in the observed changes in the Pt TOF.

The kinetics of the neopentane hydrogenolysis reaction catalyzed by the supported Pt metal particles, as presented in this study, show that $\ln A_{\text {app }}$ and $E_{\text {app }}$ follow a compensation relation. The presence of an isokinetic temperature implies also that the apparent values for $\ln A_{\text {app }}$ and $E_{\text {app }}$ are correlated with the intrinsic kinetic parameters via the thermodynamic properties of the sorption of the reactants. It is established in the literature that the reaction rate for alkane hydrogenolysis is first order in the alkane partial pressure while the order in hydrogen partial pressure is negative [22,28]. This order in hydrogen is also dependent on the reaction temperature [52] and the support [23,28]. The fact that the reaction is non-zero-order in the reactants, as found in the literature, fully supports the conclusion that the experimentally determined kinetic parameters as determined in this study are apparent values.

Details about the sorption of the reactants have been obtained in this study. It has been found that the hydrogen absorption site strongly depends on the acid/base properties of the support. The XANES signature for the hydrogen absorption site shows that hydrogen adsorbs in atop sites near the edges of Pt particles dispersed on acidic supports and on threefold Pt sites when the support is basic (Fig. 6). A combination of density functional calculations and the analysis of the XANES data lead us to the conclusion that during reaction conditions the hydrogen coverage also depends on the acid/base properties of the support. Fig. 9 makes it clear that the coverage with hydrogen is lower for Pt particles on acidic supports than on basic supports. Another important factor is revealed by the results shown in Fig. 8. The acid/base properties of the support have a much larger impact on the $\mathrm{Pt}-\mathrm{H}$ bonding than on the Pt-alkane bonding. This is mostly due to the large influence of the IBO orbitals on the Pt-H bonding. Using the results obtained in this study it is now possible to determine the causal relationship between the changes in the electronic structure and the changes in the catalytic reactivity as mentioned in the introduction.

\subsection{Effect of support acid/base properties on neopentane coverage and $T O F$}

Assuming Langmuir-Hinshelwood kinetics on the Pt surface, the TOF can be related to the neopentane (NP), $\theta_{\mathrm{NP}}$, and hydrogen $(\mathrm{H}), \theta_{\mathrm{H}}$, coverage,

$\mathrm{TOF}=\left(k_{\mathrm{B}} T / h\right) k_{\mathrm{int}} \theta_{\mathrm{NP}} \theta_{\mathrm{H}}^{\alpha}$,

with $k_{\text {int }}$ the intrinsic rate constant of the rate determining step, and assuming the order in neopentane to be 1 and the order in hydrogen coverage to be $\alpha$ for the intrinsic rate determining step. However, under the reaction conditions ( $1 \mathrm{vol} \% \mathrm{NP}$ in $\mathrm{H}_{2}$ ), adsorbed hydrogen exists in excess on the Pt surface. Therefore the gas phase neopentane $\left(\mathrm{C}_{5} \mathrm{H}_{12}\right)$ is actually in equilibrium with the $\mathrm{H}$-covered $\mathrm{Pt}$ surface,

$\mathrm{C}_{5} \mathrm{H}_{12}(\mathrm{~g})+n_{\mathrm{S}} \mathrm{S}+n_{\mathrm{d}} \mathrm{H}(\mathrm{a}) \Leftrightarrow \mathrm{C}_{5} \mathrm{H}_{12-n_{\mathrm{d}}}(\mathrm{a})+n_{\mathrm{d}} \mathrm{H}_{2}(\mathrm{~g})$,

where the model of Gault [25] has been generalized. The model allows for $n_{\mathrm{d}}$ dehydrogenation steps and requires $n_{\mathrm{s}}$ additional clean surface sites to allow the NP to adsorb.

With the assumptions that $\theta_{\mathrm{H}}$ is much larger than $\theta_{\mathrm{NP}}$, the forward, $k_{1}$, and backward, $k_{2}$, reaction rates of Eq. (9) can be given:

$k_{1}=P_{\mathrm{NP}}\left(1-\theta_{\mathrm{H}}\right)^{n_{\mathrm{s}}} \theta_{\mathrm{H}}^{n_{\mathrm{d}}}$,

$k_{2}=P_{\mathrm{H}_{2}}^{n_{\mathrm{d}}}\left(1-\theta_{\mathrm{H}}\right)^{n_{\mathrm{d}}} \theta_{\mathrm{NP}}$.

The equilibrium constant, $K_{\text {eq }}$, for Eq. (9) can then be written as

$$
\begin{aligned}
K_{\text {eq }} & =\frac{k_{2}}{k_{1}}=\frac{P_{\mathrm{H}_{2}}^{n_{\mathrm{d}} / 2}\left(1-\theta_{\mathrm{H}}\right)^{n_{\mathrm{d}}}}{\theta_{\mathrm{H}}^{n_{\mathrm{d}}}}\left[\frac{\theta_{\mathrm{NP}} P_{\mathrm{H}_{2}}^{n_{\mathrm{d}} / 2}}{P_{\mathrm{NP}}\left(1-\theta_{\mathrm{H}}\right)^{n_{\mathrm{s}}}}\right] \\
& =\mathrm{e}^{-\Delta G_{\text {eq }} / R T},
\end{aligned}
$$

where the factors are grouped for easier comparison with equations below.

The reactions for adsorption of $\mathrm{NP}$ and $\mathrm{H}_{2}$ can be written

$\mathrm{C}_{5} \mathrm{H}_{12}(\mathrm{~g})+n_{\mathrm{s}} \mathrm{S} \Leftrightarrow \mathrm{C}_{5} \mathrm{H}_{12-n_{\mathrm{d}}}(\mathrm{a})+n_{\mathrm{d}} \mathrm{H}_{2}$,

$\mathrm{H}_{2}(\mathrm{~g}) \Leftrightarrow 2 \mathrm{H}(\mathrm{a})$.

Assuming that both the neopentane and hydrogen absorption Gibbs free energy depend linearly on the $\mathrm{H}$ coverage $\left(\theta_{\mathrm{H}}\right)$, it is possible to utilize the Frumkin adsorption isotherm [53] for the adsorption of both neopentane and hydrogen, giving the equilibrium constants

$$
\begin{aligned}
& K_{\mathrm{NP}}=\frac{P_{\mathrm{H}_{2}}^{n_{\mathrm{d}} / 2} \theta_{\mathrm{NP}}}{P_{\mathrm{NP}}\left(1-\theta_{\mathrm{H}}\right)^{n_{\mathrm{s}}}}=\mathrm{e}^{-\left(\Delta G_{\mathrm{NP}}^{\mathrm{o}}+g_{\mathrm{NP}} \theta_{\mathrm{H}}\right) / R T}, \\
& K_{\mathrm{H}_{2}}=\frac{\theta_{\mathrm{H}}^{2}}{P_{\mathrm{H}_{2}}\left(1-\theta_{\mathrm{H}}\right)^{2}}=\mathrm{e}^{-\left(\Delta G_{\mathrm{H}}^{\mathrm{o}}+g_{\mathrm{H}} \theta_{\mathrm{H}}\right) / R T} .
\end{aligned}
$$


Here $P_{\mathrm{NP}}$ and $P_{\mathrm{H}_{2}}$ are the gas pressures of neopentane and $\mathrm{H}_{2}, \Delta G_{\mathrm{NP}}^{\mathrm{o}}$ and $\Delta G_{\mathrm{H}}^{\mathrm{o}}$ the neopentane and $\mathrm{H}$ adsorption Gibbs free energy (per mole NP and $\mathrm{H}_{2}$ ) at zero hydrogen coverage, and $g_{\mathrm{NP}}$ and $g_{\mathrm{H}}$ the neopentane-hydrogen and hydrogen-hydrogen lateral interaction constants. Since both $\Delta H$ and $\Delta S$ can change with coverage, the lateral interaction constants can be written $g=h-T s$. The Frumkin adsorption isotherm therefore implies here that both the neopentane and hydrogen adsorption bonds become weaker with increased hydrogen coverage. The weaker adsorption on a surface already covered with adsorbates result from either lateral interactions or from ligand effects [54] of already adsorbed species, weakening the further interaction with additional adsorbates.

Combining Eqs. (13a) and (13b) into the expression for $K_{\text {eq }}(11)$ gives

$K_{\text {eq }}=\frac{K_{\mathrm{NP}}}{K_{\mathrm{H}_{2}}^{n_{\mathrm{d}} / 2}}$.

Further combining Eqs. (13a) and (13b) into Eq. (8) leads to the appropriate rate equation for the neopentane hydrogenolysis reaction:

$$
\begin{aligned}
\mathrm{TOF} & \propto k_{\mathrm{int}} \theta_{\mathrm{NP}} \theta_{\mathrm{H}}^{\alpha} \\
& =k_{\mathrm{int}} K_{\mathrm{NP}} \theta_{\mathrm{H}}^{\alpha}\left(1-\theta_{\mathrm{H}}\right)^{n_{\mathrm{s}}} P_{\mathrm{NP}} P_{\mathrm{H}_{2}}^{-n_{\mathrm{d}} / 2} \\
& =k_{\mathrm{int}} K_{\mathrm{NP}} \theta_{\mathrm{H}}^{\alpha+n_{\mathrm{s}}} K_{\mathrm{H}_{2}}^{-n_{\mathrm{s}} / 2} P_{\mathrm{NP}} P_{\mathrm{H}_{2}}^{-\left(n_{\mathrm{d}}+n_{\mathrm{s}}\right) / 2} .
\end{aligned}
$$

This equation assumes that the change in number of vacant sites for the NP to adsorb onto is actually more important in the kinetics than the change in the excess adsorbed $\mathrm{H}$ (i.e., since $\theta_{\mathrm{H}}$ is near one, $1-\theta_{\mathrm{H}}$ is changing much faster than $\left.\theta_{\mathbf{H}}\right)$. Thus the reaction is inhibited by hydrogen adsorbed on the surface. Indeed negative orders from -1.5 to -2.5 have been reported in hydrogen pressure [24-27], implying that $n_{\mathrm{d}}+n_{\mathrm{s}}$ as defined in this work can vary from 3 to 5 . As $\theta_{\mathrm{H}}$ decreases to very small values, such as at high $T$ or low hydrogen gas pressure, the incremental change in $\theta_{\mathrm{H}}$ is more important, but then $1-\theta_{\mathrm{H}}$ approaches one. Under these conditions, Eq. (15a) becomes

$$
\begin{aligned}
\mathrm{TOF} & \propto k_{\mathrm{int}} \theta_{\mathrm{NP}} \theta_{\mathrm{H}}^{\alpha} \\
& =k_{\mathrm{int}} K_{\mathrm{NP}} \theta_{\mathrm{H}}^{\alpha}\left(1-\theta_{\mathrm{H}}\right)^{n_{\mathrm{s}}} P_{\mathrm{NP}} P_{\mathrm{H}_{2}}^{-n_{\mathrm{d}} / 2} \\
& =k_{\mathrm{int}} K_{\mathrm{NP}}\left(1-\theta_{\mathrm{H}}\right)^{\alpha+n_{\mathrm{s}}} K_{\mathrm{H}_{2}}^{\alpha / 2} P_{\mathrm{NP}} P_{\mathrm{H}_{2}}^{\left(\alpha-n_{\mathrm{d}}\right) / 2},
\end{aligned}
$$

indicating that the order in hydrogen gas pressure becomes $\left(\alpha-n_{\mathrm{d}}\right) / 2$, which is generally positive. Thus the hydrogen order is predicted to change from negative to positive with decreasing hydrogen gas pressure or increasing $T$ consistent with previously reported experimental results [52].

We assume here that the conditions expressed by Eq. (15a) are appropriate for this work. It is straightforward, from Eq. (15a), to derive the expression

$\ln \mathrm{TOF}=C+\ln A-E / R T$,

where $C \propto \ln \left[P_{\mathrm{NP}} P_{\mathrm{H}_{2}}^{-\left(n_{\mathrm{d}}+n_{\mathrm{s}}\right) / 2} \theta_{\mathrm{H}}^{n_{\mathrm{s}}+\alpha}\right]$ and with $A$ and $E$ the nominal preexponential factor and activation energy, defined as

$$
\begin{gathered}
E=\Delta H_{\mathrm{int}}^{ \pm}+\Delta H_{\mathrm{NP}}^{\mathrm{o}}+h_{\mathrm{NP}} \theta_{\mathrm{H}}-\frac{n_{\mathrm{s}}}{2}\left(\Delta H_{\mathrm{H}}^{\mathrm{o}}+h_{\mathrm{H}} \theta_{\mathrm{H}}\right), \quad(17) \\
\ln A=\left(\Delta S_{\mathrm{int}}^{ \pm}+\Delta S_{\mathrm{NP}}^{\mathrm{o}}+s_{\mathrm{NP}} \theta_{\mathrm{H}}-\frac{n_{\mathrm{s}}}{2}\left(\Delta S_{\mathrm{H}}^{\mathrm{o}}+s_{\mathrm{H}} \theta_{\mathrm{H}}\right)\right) / R .
\end{gathered}
$$

Here, $\Delta H$ and $\Delta S$ are the enthalpy and entropy changes per mole NP or $\mathrm{H}_{2}$ for the intrinsic rate-determining step (int) and neopentane (NP) and hydrogen adsorption $(\mathrm{H})$ steps. Again, since we are assuming relatively large coverage of $\mathrm{H}$ under reaction conditions, the factor $\theta_{\mathrm{H}}^{n_{\mathrm{S}}+\alpha}$ in the constant $\mathrm{C}$ is near one.

The expression $\Delta H_{\mathrm{H}}^{\mathrm{o}}+h_{\mathrm{H}} \theta_{\mathrm{H}}$ in parentheses on the right side of Eq. (17) is the differential enthalpy change at hydrogen coverage $\theta_{\mathrm{H}}$, with $\Delta H_{\mathrm{H}}^{\mathrm{o}}$ the adsorption enthalpy change at zero hydrogen coverage. With increasing $\mathrm{H}$ coverage the differential enthalpy is increasing (decreasing in magnitude), until the last $\mathrm{H}$ atoms are added reversibly; i.e., a small change in temperature or pressure will either decrease or increase the hydrogen coverage. Therefore the final Gibbs free energy is zero for the reversible adsorption of $\mathrm{H}$,

$$
\begin{aligned}
\Delta G_{H, r} & =\Delta G_{\mathrm{H}}^{\mathrm{o}}+g_{\mathrm{H}} \theta_{\mathrm{H}, \mathrm{r}}=0 \\
& =\Delta H_{\mathrm{H}}^{\mathrm{o}}+h_{\mathrm{H}} \theta_{\mathrm{H}, \mathrm{r}}-T\left(\Delta S_{\mathrm{H}}^{\mathrm{o}}+s_{\mathrm{H}} \theta_{\mathrm{H}, \mathrm{r}}\right),
\end{aligned}
$$

where $\Delta H_{\mathrm{H}}^{\mathrm{o}}+h_{\mathrm{H}} \theta_{\mathrm{H}, \mathrm{r}}$ will be called the reversible heat of adsorption and $\theta_{\mathrm{H}, \mathrm{r}}$ is the coverage reached at this point. This heat of adsorption of the reversible hydrogen is closely related to the isoteric heat of adsorption defined in other references [55], but it is not necessarily the same. It is the weakest bonded $\mathrm{H}$ that desorbs to create vacant sites for NP to adsorb. Therefore the effective enthalpy to include in $E$ is that of the reversibly adsorbed $\mathrm{H}$. It is now possible to rewrite Eq. (17):

$$
E=\Delta H_{\mathrm{int}}^{ \pm}+\Delta H_{\mathrm{NP}}^{\mathrm{o}}+h_{\mathrm{NP}} \theta_{\mathrm{H}, \mathrm{r}}-\frac{n_{\mathrm{s}} T}{2}\left(\Delta S_{\mathrm{H}}^{\mathrm{o}}+s_{\mathrm{H}} \theta_{\mathrm{H}, \mathrm{r}}\right) .
$$

Combining Eqs. (16), (18), and (20) gives

$$
\begin{aligned}
\ln \mathrm{TOF}= & C+\left(\Delta S_{\mathrm{int}}^{ \pm}+\Delta S_{\mathrm{NP}}^{\mathrm{o}}\right) / R-\left(\Delta H_{\mathrm{int}}^{ \pm}+\Delta H_{\mathrm{NP}}^{\mathrm{o}}\right) / R T \\
& -g_{\mathrm{NP}} \theta_{\mathrm{H}, \mathrm{r}} / R T,
\end{aligned}
$$

showing that the change in order of hydrogen cancels out of the expression for the TOF, except for $n$ in the constant $\mathrm{C}$. Note that the $\Delta S_{\mathrm{NP}}^{\mathrm{o}} / R$ and $\left(\Delta H_{\mathrm{NP}}^{\mathrm{o}}+g_{\mathrm{NP}} \theta_{\mathrm{H}, \mathrm{r}}\right) / R T$ terms do not cancel, as the similar terms did for $\mathrm{H}_{2}$, because NP has very low coverage on the surface compared to $\mathrm{H}_{2}$, and therefore a significant portion of it is reacting to form products.

To evaluate the difference between the TOF with the acid/base support properties, the following expression can be derived from Eq. (21),

$\ln \left(\mathrm{TOF}_{x} / \mathrm{TOF}_{\mathrm{ref}}\right)=\delta C-g_{\mathrm{NP}} \delta \theta_{\mathrm{H}, \mathrm{r}} / R T$, 


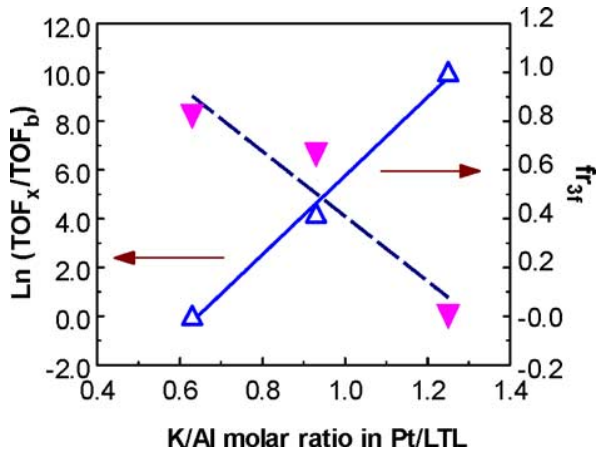

(a)

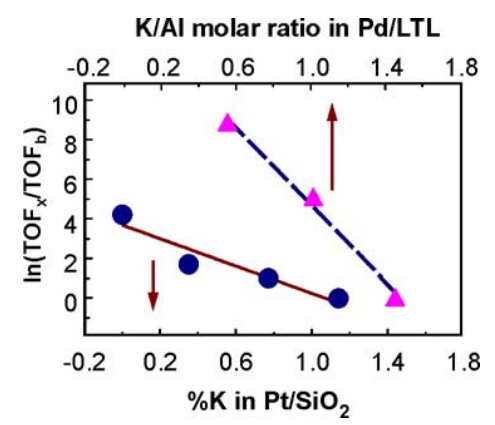

(b)

Fig. 10. (a) Plot of the experimental $\ln \left(\mathrm{TOF}_{x} / \mathrm{TOF}_{\mathrm{b}}\right)$ for neopentane hydrogenolysis on small Pt clusters supported in $\operatorname{LTL}(x)$ zeolite, against the indicated alkalinity scale $\left(x=\right.$ molar $\mathrm{K} / \mathrm{Al}$ ratio). Here $\mathrm{TOF}_{\mathrm{b}}$ is for the most basic support $(x=1.25)$. Also plotted is the fraction of threefold $\mathrm{H}$ as obtained from the analysis of the XANES data described in the text, where the fractions of threefold $\mathrm{H}$ were assumed to be 0 and 1 for the most basic and acidic supports as suggested from the theoretical fingerprints shown in Fig. 3. (b) Similar plot of $\ln \left(\mathrm{TOF}_{x} / \mathrm{TOF}_{\mathrm{b}}\right)$ for Pd clusters in LTL zeolite. Also shown are similar data for $\mathrm{Pt} / \mathrm{SiO}_{2}$, except the alkalinity scale is now $\% \mathrm{~K}$ in the $\mathrm{SiO}_{2}$.

where $\delta$ indicates the difference between some general support, $x$, and a reference support (ref). $\delta C$ is essentially zero in this work, because although the order in $\mathrm{H}$ changes with acidity, $P_{\mathrm{H}_{2}}$ and $\theta_{\mathrm{H}, \mathrm{r}}$ are both near one. It has also been assumed that $\delta \Delta H_{\mathrm{NP}}^{\mathrm{o}}$ can be ignored, as shown above (and therefore also $\delta \Delta S_{\mathrm{NP}}^{\mathrm{o}}$ ), and that the intrinsic ratedetermining step is not affected by the support.

The experimentally obtained $\ln \left(\mathrm{TOF}_{x} / \mathrm{TOF}_{\mathrm{ref}}\right)$ as obtained from data previously reported for Pt/LTL [20] is plotted in Fig. 10a versus the $\mathrm{K} / \mathrm{Al}$ molar ratio. In Fig. 10a $\ln \left(\mathrm{TOF}_{x} / \mathrm{TOF}_{\text {basic }}\right)$ is shown with the most basic support chosen as the reference for convenience; changing the reference only adds a constant. The variation in alkalinity of the LTL zeolite can be expressed as the $\mathrm{K} / \mathrm{Al}$ ratio. Also plotted in Fig. 10a is the fraction of threefold hydrogen assuming only atop $\mathrm{H}$ for the most acidic $\left(\theta_{\mathrm{H}, \mathrm{a}}\right)$ and threefold $\mathrm{H}$ for the most basic $\left(\theta_{\mathrm{H}, \mathrm{b}}\right)$ and using the intermediate result given by Eq. (4). With these assumptions, $\theta_{\mathrm{H}}$ can be expressed as

$$
\begin{aligned}
\theta_{\mathrm{H}} & =\theta_{\mathrm{H}, \mathrm{a}}+f r_{3 f}\left(\theta_{\mathrm{H}, \mathrm{b}}-\theta_{\mathrm{H}, \mathrm{a}}\right) \ldots \quad \text { or } \\
\delta \theta_{\mathrm{H}} & =\theta_{\mathrm{H}}-\theta_{\mathrm{H}, \mathrm{a}}=c f r_{3 f},
\end{aligned}
$$

where $c$ is a constant, showing that $\delta \theta_{\mathrm{H}}$ (with reference chosen as the most acidic support) is proportional to the fraction of threefold $\mathrm{H}, f r_{3} f$. The linear behavior of both plots in Fig. 10a confirms Eq. (22). A linear behavior is also observed in Fig. 10b for the previously reported Pd/LTL and $\mathrm{Pt} / \mathrm{K}-\mathrm{SiO}_{2}$ data [17] with varying $\mathrm{K} / \mathrm{Al}$ ratio and various amount of $\mathrm{K}(\%)$, respectively, as the alkalinity scale.

\subsection{Negative order in hydrogen and compensation relation}

Fig. 4 shows a linear relationship between $\ln A_{\mathrm{pp}}$ and $E_{\text {app }}$ for the $\mathrm{Pt} / \mathrm{Y}$ catalysts, which is the compensation relation. Based on Eqs. (18), (20), and (21), these can now be written

$$
\begin{aligned}
E_{\mathrm{app}} & =\Delta H_{\mathrm{int}}^{ \pm}+\Delta H_{\mathrm{NP}}^{\mathrm{o}}+h_{\mathrm{NP}} \theta_{\mathrm{H}, \mathrm{r}}, \\
\ln A_{\mathrm{app}} & =\left(\Delta S_{\text {int }}^{ \pm}+\Delta S_{\mathrm{NP}}^{\mathrm{o}}+s_{\mathrm{NP}} \theta_{\mathrm{H}, \mathrm{r}}\right) / R .
\end{aligned}
$$

The dominant variable in $\ln A_{\mathrm{pp}}$ and $E_{\mathrm{app}}$ with change in support is the coverage of hydrogen. Therefore the linear relationship in Eq. (1) indicates

$\frac{s_{\mathrm{NP}} \theta_{\mathrm{H}, \mathrm{r}}}{R}=m h_{\mathrm{NP}} \theta_{\mathrm{H}, \mathrm{r}}$,

so that the slope, $m$, in Fig. 4 equals $s_{\mathrm{NP}} /\left(h_{\mathrm{NP}} R\right)$. But $g_{\mathrm{NP}}=h_{\mathrm{NP}}-T_{i} s_{\mathrm{NP}}=0$ at the isokinetic temperature, $T_{i}$; therefore $T_{i}=h_{\mathrm{NP}} / s_{\mathrm{NP}}$ and $m=1 / R T_{i}$. Thus the isokinetic temperature can be determined from Fig. 4, and combining Eq. (22) with the expression for $T_{i}$ gives

$\ln \left(\mathrm{TOF}_{x} / \mathrm{TOF}_{\mathrm{ref}}\right)=-s_{\mathrm{NP}} \delta \theta_{\mathrm{H}, \mathrm{r}}\left(T_{i}-T\right) / R T$,

where we have assumed that $\delta C$ is negligible, since $P_{\mathrm{H}_{2}}$ and $\theta_{\mathrm{H}, \mathrm{r}}$ are both near 1 . Eq. (26) shows that the metalsupport effect decreases to zero as the reaction temperature approaches $T_{i}$.

Fig. 4 shows $\ln A_{\text {app }}$ varying over a range of about 10 for the data plotted, giving an estimate for $\left|\left(s_{\mathrm{NP}} / R\right) \delta \theta_{\mathrm{H}, \mathrm{r}}\right|$ for the data considered in Fig. 4. The slope $m$ of the ConstableCremer plot, $10 / 60,000=0.000167$, indicates that the isokinetic temperature, $T_{i}$, is around $700 \pm 100 \mathrm{~K}$. This value for $T_{i}$ is confirmed by data similar to those reported in Table 1 and Fig. 4 for the same supports and particle sizes ([48]; de Graaf, van Bokhoven, and Koningsberger, in preparation), but run at a much higher temperature of $673 \mathrm{~K}$. These data show that the TOF varies less steeply with support acidity, and indeed varies in the opposite direction, suggesting that $T_{i}$ is actually around $650 \mathrm{~K}$, well within the range predicted here.

At our reaction conditions and temperature $(523 \mathrm{~K})$, the maximum value of $\ln \left(\mathrm{TOF}_{\mathrm{a}} / \mathrm{TOF}_{\mathrm{b}}\right)$ obtainable from Eq. (26) is $10(700-523) / 523=3.4$ for the data considered, which is indeed just slightly larger than, for example, the experimental value of 3.3 from Table 1 for the $\ln \left(\mathrm{TOF}_{\mathrm{HUSY}} / \mathrm{TOF}_{\mathrm{NaY}}\right)$ supports, which span a relatively large acidity range. However, Figs. $10 \mathrm{a}$ and $10 \mathrm{~b}$ show maximum $\ln \left(\mathrm{TOF}_{\mathrm{a}} / \mathrm{TOF}_{\mathrm{b}}\right)$ values of up to 9 , indicating that much larger ranges occur for Pt/LTL and Pd/LTL, where the metal particle size is much smaller (Y zeolite: $N_{\mathrm{Pt}-\mathrm{Pt}}=6$ compared with LTL zeolite: $\left.N_{\mathrm{Pt}-\mathrm{Pt}}=4\right)$. The particle size, and 
maybe other variables also, enters into the maximum range of $\delta \theta_{\mathrm{H}}$. Much more work is required here to further clarify the effects on $\delta \theta_{\mathrm{H}}$. Although $h_{\mathrm{NP}}$ may change as the lateral interaction decreases with decrease in hydrogen coverage (i.e., with increasing $T$ ) the straight-line Arrhenius plots (not shown here) used to obtain the $E_{\text {app }}$ [48] indicate a constant $E_{\text {app }}$, and hence a constant $h_{\mathrm{NP}}$ over the temperature range of the Arrhenuis plots. The straight line Compton-Cremer plot (Fig. 4) suggests then that both $h_{\mathrm{NP}}$ and $s_{\mathrm{NP}}$ are constant over the coverage range of the acid and basic supports in this work. Thus the Frumkin isotherms, which assume that the neopentane adsorption free energy depends linearly with the hydrogen coverage, is confirmed. This verifies the basis of the kinetics in this work.

Finally we give a comment on the order in hydrogen and its change with support acidity. Our experimental XANES data show that as the hydrogen coverage decreases with increased acidity of the support, the hydrogen moves to the atop site. We suggest that this change in $\mathrm{H}$ binding site is responsible for the change in hydrogen reaction order with support alkalinity. For neopentane to adsorb, $n_{\mathrm{s}}$ vacant sites are required according to Eq. (9). Literature data show a negative order in $\mathrm{H}_{2}$ of $-3 / 2$ on acidic supports, and therefore suggest that on a acidic support around 2 vacant atop sites are required for one dehydrogenation step, $\left(n_{\mathrm{d}}+\right.$ $\left.n_{\mathrm{s}}\right)=(1+2)=3$. In contrast, the change to $-5 / 2$ on basic supports suggests an $\left(n_{\mathrm{d}}+n_{\mathrm{s}}\right)$ combination of either $(1+4)$ or $(2+3)$. The $\mathrm{H}$ location in threefold binding sites on basic supports suggests that an increased number of vacant threefold sites are required for the NP adsorption, so that either the $(1+4)$ or $(2+3)$ combinations are reasonable. Some further NP dehydrogenation (i.e., $\left(n_{\mathrm{d}}+n_{\mathrm{s}}\right)=(2+$ 3)) may be taking place on basic supports. This might be responsible for the change in selectivity with support, but more work is required to verify this.

\subsection{Energy scheme of adsorption and kinetics}

Fig. 11 summarizes the proposed mechanism and energetics of the adsorption and kinetics utilized in this work. It incorporates the results of the DFT calculations on the very small $\mathrm{Pt}_{4}$ clusters considered and the XANES analysis on the small supported Pt clusters $(N=4-6)$ and illustrates the kinetics incorporated into the equations discussed above.

The DFT results show that the importance of the Pt $6 s, p$ states in the chemisorption bond increases in the order $\mathrm{CH}_{2}<\mathrm{CH}_{3}<\mathrm{H}$ on the small $\mathrm{Pt}_{4}$ clusters studied. The Pt $6 s$ and $6 p$ states are influenced strongly by the support acidity, thereby influencing the bonding of the adsorbates. On acidic supports, the $s p$ states are moved toward the metal-support interface, and consequently the adsorbate bond energies are decreased. However, on basic supports the Pt $6 s, p$ states are located at the surface of the Pt cluster and are readily available for the bonding to adsorbates. Consequently, the Pt-adsorbate bond strength is increased on a basic support. When the Pt $6 s, p$ orbitals are less important

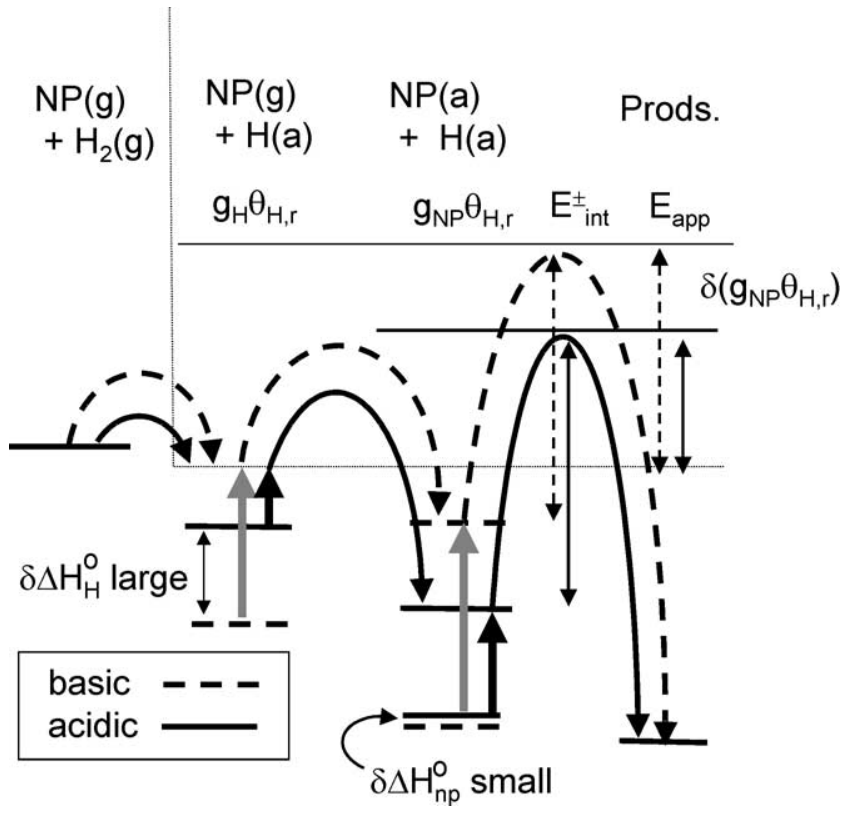

Fig. 11. Proposed mechanism for neopentane (NP) hydrogenolysis and energy scheme for each step comparing the case for acidic (solid) and basic (dotted) supports. Items in top line indicate the molecular species at each step. Items in second line define the double arrows immediately below each item. Various difference components $(\delta)$ indicate the difference between the most acidic minus basic supports. Bold arrows indicate relative magnitudes of $g \theta_{\mathrm{H}, \mathrm{r}} . E_{\mathrm{int}}$ is determined by $\Delta H_{\mathrm{int}}^{ \pm}, E_{\mathrm{app}}$ is measured experimentally.

in the chemisorption, as is the case for $\mathrm{CH}_{2}$ bonding, the $5 d$ band dictates the bond energy. In this case the Pt-adsorbate bond may be slightly stronger for acidic supports than for basic supports, or not affected at all. These differences are shown by the $\delta \Delta H_{\mathrm{H}}^{\mathrm{o}}$ and $\delta \Delta H_{\mathrm{NP}}^{\mathrm{o}}$ relative sizes in Fig. 11 .

Fig. 11 shows how the large $\delta \Delta H_{\mathrm{H}}^{\mathrm{O}}$ determines the energetics, by causing a larger $\mathrm{H}$ coverage for basic supports than for acidic. This in turn causes the order in $\mathrm{H}_{2}$ to change, being $-3 / 2$ on acidic supports at lower coverage, vs $-5 / 2$ on basic supports at higher coverage. The DFT calculations show that at lower coverage $\mathrm{H}$ prefers the atop sites near the cluster edges or corners, and the XANES data indeed reveal that this atop adsorption dominates on highly acidic supports. The change in order is believed to occur directly as a result of a geometric rearrangement (i.e., $\mathrm{H}$ binding site change). The change in enthalpy for adsorption of the neopentane with support acidity is determined almost completely by the amount of $\mathrm{H}$ adsorbed assuming the Frumkin adsorption isotherm. As revealed in Fig. 11, this determines the activation energy. Thus as we have shown in Fig. 10a, the relative TOFs track directly with the change in $\mathrm{H}$ coverage. The intrinsic $E_{\text {int }}$ is assumed not to be influenced by the change in hydrogen coverage. The qualitative explanation of the neopentane kinetics in terms of a change in the hydrogen coverage induced by the support makes it unnecessary to have a change in the intrinsic kinetic properties. 


\subsection{Implications for catalytic research in the future: preparation of tailor-made catalysts}

The acid/base properties and composition of the support are important parameters for influencing the catalytic properties of supported metal particles. This study reveals, for very small $\mathrm{Pt}$ clusters, the causal relationship between the change in catalytic reactivity and electronic properties of the metal particles. Previous work by our group and others has shown that changes in the electronic and geometric properties of the metal particles induced by changes in the support can be followed with XAFS spectroscopy (Atomic XAFS, XANES, and EXAFS). The results of this study therefore could ultimately lead to the preparation of tailor-made catalysts with predictable results. For instance, a catalytic reaction with catalytic intermediates that need metal surface valence orbitals with electron acceptor or donor properties requires a metal particle to be prepared on a support with oxygen atoms having a lower (acidic support) or higher (basic support) electron charge. For zeolitic supports, the composition can be tuned by introducing protons, changing cations or $\mathrm{Si} / \mathrm{Al}$ ratio, or steaming (leads to the presence of extra-framework $\mathrm{Al}$ ). Not only hydrogenolysis reactions as studied in this work, but also the hydrogenation activity of supported Pt is predictably influenced by the acid/base properties and composition of the support. For instance, a catalyst for aromatic saturation can be made sulfur-tolerant (high catalytic activity in the presence of sulfur) by making the support acidic, by increasing the polarization power of the charge-compensating cations, by decreasing the $\mathrm{Si} / \mathrm{Al}$ ratio, and by introducing extra-framework Al. More research will reveal the details of these changes in catalytic reactivity.

The concept of changing the catalytic properties of supported metal particles by changing the acid/base properties and composition of the support can be further extended to the metal-oxide and metal-sulfide support interaction. Preliminary studies in our laboratory indeed have shown that the electronic structure of supported vanadium oxides is strongly influenced by the acid/base properties of the support. This is consistent with changes in the catalytic properties, as observed in the literature.

The signature for the mode or site of absorption, as obtained in this study for hydrogen, can also be obtained for the adsorption of oxygen and sulfur. The XANES results recently obtained by Teliska et al. (submitted) for hydrogen and oxygen adsorption on $\mathrm{Pt} /$ carbon electrodes show prominent changes in the mode of adsorption as a function of the applied potential. The applied potential determines the coverage of these reactants. Finally, recent oxygen and sulfur poisoning studies of supported Pt catalysts carried out in our laboratory reveal that the mode of adsorption of $\mathrm{O}$ and $\mathrm{S}$ is also dependent on the acid/base properties and the composition of the support. Therefore the analysis methods outlined in this work could lead in the future to a more detailed picture of catalytic reactions, at the molecular scale, in a large number of reactions.

\section{Conclusions}

This study shows that the differential $\mathrm{Pt}-\mathrm{H}$ heat of adsorption at low coverage (i.e., $\Delta H^{\mathrm{o}}$, or the inherent Pt$\mathrm{H}$ bond strength) drives the kinetics for the hydrogenolysis reaction catalyzed by $\mathrm{Pt}$. The inherent $\mathrm{Pt}-\mathrm{H}$ bond strength determines (i) the $\mathrm{H}$ coverage, (ii) the negative order in $\mathrm{H}_{2}$, and ultimately (iii) the Pt neopentane coverage. The ADF calculations done on small $\mathrm{Pt}_{4}$ clusters in this work, indicate that the inherent $\mathrm{Pt}-\mathrm{H}$ bond strength is driven by the placement of the interstitial bond orbital (IBO) relative to the $\mathrm{Pt}-\mathrm{H}$ bond. As the IBO moves toward the outer surface, the $\mathrm{Pt}-\mathrm{H}$ bond strength increases, and it decreases as the IBO moves toward the $\mathrm{Pt}-$ support interface. The placement of the IBO is determined by the support alkalinity. Therefore the support alkalinity determines the inherent $\mathrm{Pt}-\mathrm{H}$ bond strength, and this ultimately causes a change in coverage and bond strength of both the $\mathrm{H}$ and the alkane. In this work, a direct correlation between the metal-support interaction and the kinetics of neopentane hydrogenolysis is provided. Further work is required to confirm that the IBO placement effect on adsorbate bond strengths is also active on larger clusters and that it dominates in other reactions involving $\mathrm{H}_{2}$, such as hydrogenation and H/D exchange.

\section{Acknowledgments}

The authors thank the scientific staff of Station 9.2 at the SRS (Daresbury, UK) and of BM29 at the ESRF (Grenoble, France). The authors also thank the editor, Professor Nick Delgass, for suggestions and careful reading of this manuscript.

\section{References}

[1] W. Penn, Oil and Gas Journal Data Book, Tulsa, OK, 1994.

[2] F. Figueras, J.R. Gomez, M. Primet, Adv. Chem. Ser. 121 (1973) 480.

[3] S.D. Lin, M.A. Vannice, J. Catal. 143 (1993) 539.

[4] M. Vaarkamp, J.T. Miller, F.S. Modica, G.S. Lane, D.C. Koningsberger, in: Proceedings 10th International Congress on Catalysis, Budapest, 1992, p. 809.

[5] Z. Karpinski, S.N. Gandhi, W.H.M. Sachtler, J. Catal. 141 (1993) 337.

[6] S.T. Homeyer, Z. Karpinski, W.M.H. Sachtler, J. Catal. 123 (1990) 60.

[7] R.A. Dalla Betta, M. Boudart, in: J.W. Hightower (Ed.), Proceeding 5th International Congress on Catalysis, Vol. 2, North-Holland, Amsterdam, 1973, p. 1329.

[8] Z. Zhang, T.T. Wong, W.M.H. Sachtler, J. Catal. 128 (1991) 13.

[9] G. Larsen, G.L. Haller, Catal. Lett. 3 (1989) 103.

[10] A. de Mallmann, D. Barthomeuf, J. Chem. Phys. 87 (1990) 535.

[11] A. de Mallmann, D. Barthomeuf, Stud. Surf. Sci. Catal. 46 (1989) 429.

[12] M. Sugimoto, H. Katsuno, T. Hayasaka, N. Ishikawa, K. Hirasawa, Appl. Catal. A Gen. 102 (1993) 167.

[13] A.P. Jansen, R.A. van Santen, J. Phys. Chem. 94 (1990) 6764

[14] E. Sanchez-Marcos, A.P.J. Jansen, R.A. van Santen, Chem. Phys. Lett. 16 (1990) 399. 
[15] V. Ponec, G.C. Bond, in: Catalysis by Metals and Alloys, in: Studies Surface Science Catalysis, Vol. 95, Elsevier, Amsterdam, 1995, p. 234.

[16] D.C. Koningsberger, M.K. Oudenhuijzen, D.E. Ramaker, J.T. Miller, in: A. Corma, F.V. Melo, S. Mendioroz, J.L.G. Fierro (Eds.), 12th International Congress on Catalysis, in: Studies Surface Science Catalysis, Vol. 130, Elsevier, Amsterdam, 2000, p. 317.

[17] B.L. Mojet, M.J. Kappers, J.T. Miller, D.C. Koningsberger, in: Proceedings of the 11th International Congress on Catalysis, in: Studies Surface Science Catalysis, Vol. 101, Elsevier, Amsterdam, 1996, p. 1165.

[18] D.C. Koningsberger, J. de Graaf, B.L. Mojet, D.E. Ramaker, J.T. Miller, Appl. Catal. A 191 (2000) 205.

[19] D.E. Ramaker, J. de Graaf, J.A.R. van Veen, D.C. Koningsberger, J. Catal. 203 (2001) 7.

[20] B.L. Mojet, J.T. Miller, D.E. Ramaker, D.C. Koningsberger, J. Catal. 186 (1999) 373.

[21] M.K. Oudenhuijzen, PhD thesis, Utrecht University, 2002.

[22] J.H. Sinfelt, Catal. Rev. 3 (1969) 175.

[23] G.A. Martin, R. Dutartre, S. Yuan, X. Márquez-Alvarez, C. Mirodatos, J. Catal. 177 (1998) 105.

[24] G.C. Bond, Catal. Today 17 (1993) 399.

[25] F.G. Gault, Adv. Catal. 30 (1981).

[26] K. Foger, J.R. Anderson, J. Catal. 54 (1978) 318.

[27] P.V. Menacherry, G.L. Haller, J. Catal. 167 (1997) 425.

[28] G.C. Bond, M.A. Keane, H. Kral, J.A. Lercher, Catal. Rev. Sci. Eng. 42 (2000) 323.

[29] A.K. Galwey, Thermochim. Acta 294 (1997) 205.

[30] A. Wootsch, Z. Paál, J. Catal. 205 (2002) 86.

[31] F.H. Constable, Proc. Roy. Soc. (London) A 108 (1925) 355.

[32] G.C. Bond, M.A. Keane, H. Kral, J.A. Lercher, Catal. Rev. Sci. Eng. 42 (2000) 323.

[33] M. Tempkin, Acta Physicochim. URSS 3 (1935) 312.

[34] J. de Graaf, A.J. van Dillen, K.P. de Jong, D.C. Koningsberger, J. Catal. 203 (2001) 307.

[35] M. Vaarkamp, B.L. Mojet, F.S. Modica, J.T. Miller, D.C. Koningsberger, J. Phys. Chem. 99 (1995) 16067.
[36] Amsterdam Density Functional Package ADF 2000.02, Department of Theoretical Chemistry, Vrije Universiteit, Amsterdam, available at: http://www.scm.com.

[37] A.L. Ankudinov, B. Ravel, J.J. Rehr, S.D. Conradson, Phys. Rev. B 58 (1998) 7565.

[38] F.W. Lytle, R.B. Greegor, E.C. Marques, V.A. Biebesheimer, D.R. Sandstrom, A. Horsley, G.H. Via, J.H. Sinfelt, ACS Symp. Ser. 288 (1985) 280.

[39] T. Kubota, K. Asakura, N. Ichikuni, Y. Iwasawa, Chem. Phys. Lett. 256 (1996) 445.

[40] S.N. Reifsnyder, M.M. Otten, D.E. Sayers, H.H. Lamb, J. Phys. Chem. B 101 (1997) 4972.

[41] D.E. Ramaker, B.L. Mojet, M.T. Garriga Oostenbrink, J.T. Miller, D.C. Koningsberger, Phys. Chem. Chem. Phys. 1 (1999) 2293.

[42] P.J. Feibelman, D.R. Hamann, Surf. Sci. 182 (1987) 411.

[43] G. Papoian, J.K. Nørskov, R. Hoffmann, J. Am. Chem. Soc. 122 (2000) 4129.

[44] A.L. Ankudinov, J.J. Rehr, J. Low, S.R. Bare, Phys. Rev. Lett. 86 (2001) 1642.

[45] D.E. Ramaker, D.C. Koningsberger, Phys. Rev. Let. E 89 (2002) 139701.

[46] B.L. Mojet, D.E. Ramaker, J.T. Miller, D.C. Koningsberger, Catal. Lett. 62 (1999) 15.

[47] D.C. Koningsberger, M.K. Oudenhuijzen, J.H. Bitter, D.E. Ramaker, Top. Catal. 10 (2000) 167.

[48] J. de Graaf, PhD thesis, Utrecht University, 2001.

[49] J. Kua, W.A. Goddard III, J. Phys. Chem. B 102 (1998) 9481.

[50] S.M. Davis, G.A. Somorjai, in: D.A. King, D.P. Woodruff (Eds.), The Chemical Physiscs of Solid Surfaces and Heterogeneous Catalysts, Vol. 4, Elsevier, Amsterdam, 1982, p. 271.

[51] J.R. Anderson, N.R. Avery, J. Catal. 16 (1967) 315.

[52] C.J. Machiels, R.B. Anderson, J. Catal. 58 (1979) 253.

[53] C.M.A. Brett, in: Electrochemistry, Principles, Methods, and Applications, Vol. 55, Oxford Science, Oxford, 2000.

[54] A.M. Argo, J.F. Odzak, F.S. Lai, B.C. Gates, Nature 415 (2002) 623.

[55] Q. Ge, R. Kose, D.A. King, Adv. Catal. 45 (2000) 207. 